\title{
Review
}

\section{The Neuroprotective Effects of Exercise: Maintaining a Healthy Brain Throughout Aging}

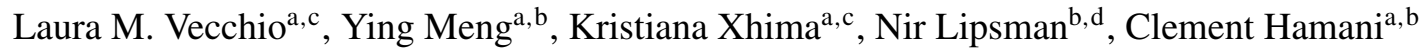 \\ and Isabelle Aubert ${ }^{\mathrm{a}, \mathrm{c}, *}$ \\ ${ }^{a}$ Biological Sciences, Hurvitz Brain Sciences Research Program, Sunnybrook Research Institute, ON, Canada \\ ${ }^{\mathrm{b}}$ Institute of Medical Sciences, University of Toronto, ON, Canada \\ ${ }^{\mathrm{c}}$ Department of Laboratory Medicine and Pathobiology, University of Toronto, ON, Canada \\ ${ }^{d}$ Physical Sciences, Hurvitz Brain Sciences Research Program, Sunnybrook Research Institute, ON, Canada
}

Accepted: 2 September 2018

Published: 6 October 2018

\begin{abstract}
Physical activity plays an essential role in maintaining a healthy body, yet it also provides unique benefits for the vascular and cellular systems that sustain a healthy brain. While the benefit of exercise has been observed in humans of all ages, the availability of preclinical models has permitted systematic investigations into the mechanisms by which exercise supports and protects the brain. Over the past twenty-five years, rodent models have shown that increased physical activity elevates neurotrophic factors in the hippocampal and cortical areas, facilitating neurotransmission throughout the brain. Increased physical activity (such as by the voluntary use of a running wheel or regular, timed sessions on a treadmill) also promotes proliferation, maturation and survival of cells in the dentate gyrus, contributing to the process of adult hippocampal neurogenesis. In this way, rodent studies have tremendous value as they demonstrate that an 'active lifestyle' has the capacity to ameliorate a number of age-related changes in the brain, including the decline in adult neurogenesis. Moreover, these studies have shown that greater physical activity may protect the brain health into advanced age through a number of complimentary mechanisms: in addition to upregulating factors in pro-survival neurotrophic pathways and enhancing synaptic plasticity, increased physical activity promotes brain health by supporting the cerebrovasculature, sustaining the integrity of the blood-brain barrier, increasing glymphatic clearance and proteolytic degradation of amyloid beta species, and regulating microglia activation. Collectively, preclinical studies demonstrate that exercise initiates diverse and powerful neuroprotective pathways that may converge to promote continued brain health into old age. This review will draw on both seminal and current literature that highlights mechanisms by which exercise supports the functioning of the brain, and aids in its protection.
\end{abstract}

\section{INTRODUCTION}

Regular exercise plays essential role in maintaining a healthy lifestyle. It bolsters the cardiovascular, and immune and metabolic systems and in addition, modulates the internal milieu of the brain [1-6]. Both

\footnotetext{
*Correspondence to: Isabelle Aubert, E-mail: Isabelle.Aubert@ sunnybrook.ca.
}

acute, high-intensity activity and regular, moderate aerobic exercise have been reported to increase levels of circulating neurotrophic factors and enhance neurotransmission, exerting beneficial effects on mood and cognitive functions in individuals of all ages [7-16]. In young adults, an acute bout of highintensity cycling induced an increase in serum levels of brain-derived neurotrophic factor (BDNF) that correlated with blood lacate [7], as did long-term 
exercise of moderate intensity (i.e. 5 weeks of cycling, 3 times per week, at intensities below the ventilatory threshold) [8]; both regimens correlated with improved cognitive performance. Adults over 65 years of age that participated in regular exercise (e.g. walking, hiking, biking, weight-training, stretching, or others) score higher on common memory tests and have been shown to be at a reduced risk for dementia and impairment in executive functions associated with advancing age [17-21]. These benefits often correlated with measures such as frequency and/or intensity of exercise, and caloric expenditure. Exercise such as walking, aerobic exercise, and strength training, was also shown to improve executive functions and cognition in individuals already suffering from early stages of dementia [18, 22-24]. To this end, the importance of exercise in supporting continued brain health in the aging brain, even individuals affected by the early stages of neurodegeneration, is gaining recognition. Moreover, because studies suggest that physical activity can reduce the risk of cognitive decline, an active lifestyle can be thought of as a 'preventative' strategy to ameliorate the deterioration of brain health much as it is with cardiovascular dysfunction.

In humans, age-related changes in the brain commonly underlie cognitive decline; these may include progressive reductions in neurotrophic levels, alterations in the cerebrovasculature, and declining neurogenesis [25-34]. The hippocampus is particularly vulnerable to age-related morphological and functional alterations [34-39]. Similar age-related alterations have been observed in rodents, making them an ideal model for identifying changes that occur on a cellular level and for investigating interventional or preventative strategies [40-43]. As in humans, rodent models have shown age-related reductions in hippocampal volume $[38,44,45]$. This is, in part, a consequence of a decline in cell proliferation $[46,47]$ and morphologic changes in the rodent brain, such as reductions in dendritic branching, spine densities, and fibres projecting into the hippocampus [38, 42, 43, 45, 48-51]. In addition, advanced age in both rodents and humans have been associated with a reduction in trophic support to the brain, such as declining levels of BDNF and its full-length receptor, tropomyosin receptor kinase B (TrkB) [35, 37, 42]. The loss of neurotrophic support is concomitant with attenuated neuronal survival and synaptic plasticity $[29,36,43,48,50,52$, 53]. Importantly, age-related neurological changes correlate with functional decline, particularly in hippocampus-dependent learning and memory tasks, and navigational strategies [5, 54-59].

Notably, though the hippocampus is known to be a principle site of mammalian adult neurogenesis [60], there has been some discrepancy as to whether this occurs in humans [61-65]. A recent paper by Sorrells and colleagues found no evidence for neurogenesis beyond youth [64], while Boldrini et al. published a paper shortly thereafter showing that neurogenesis did in fact persist into adulthood, with a small age-related decline [61], in keeping with previous studies $[62,65]$. Indeed, numerous studies have suggested that adult-born neural stem cells may be stimulated to form distinct populations of neurons and though these cells may lose proliferative potential and become quiescent with age, they can be reactivated upon stimulation, including running [63, 66-71].

Over two decades ago, mice living in enriched cages were showed to have elevated neurogenesis in the dentate gyrus, an effect that is most remarkable in young rodents; these cages were larger, housed many mice and contained a number of accessories (including a running wheel) $[56,72,73]$. Subsequent studies dissociated the different elements of the enriched environment, and demonstrated that voluntary running alone is sufficient to increase cell proliferation and survival in the hippocampus, enhance synaptic plasticity and improve cognitive performance [54, 56, 57, 74, 75]. In young mice, treadmill training and voluntary wheel running has been consistently associated with enhanced performance on hippocampal-dependent memory tasks such as the Y-Maze and Morris water maze [54, 56, 57, 74, 76], as well as tasks that do not specifically depend on the learning or consolidation of spatial memory (i.e. contextual fear conditioning, passive avoidance learning, and novel object recognition) [75, 77-81]. In aging rodents, exercise attenuates the age-related decline in cell proliferation and differentiation [41, $54,57]$. Moreover, just one month of voluntary running ameliorates many neurological and behavioural deficits associated with aging [41, 54, 57, 82, 83]. Notably, even short bouts of mild-intensity exercise (4-6 minutes on 5 consecutive days, for 5 weeks) initiates pro-survival pathways in aged rats [82]. In addition, mice that underwent long-term voluntary running throughout middle-age exhibited improved performance on spatial memory tasks later in life, which correlated with an increase in BDNF levels and enhanced neurogenesis in the dentate gyrus [41, $54,76]$. 

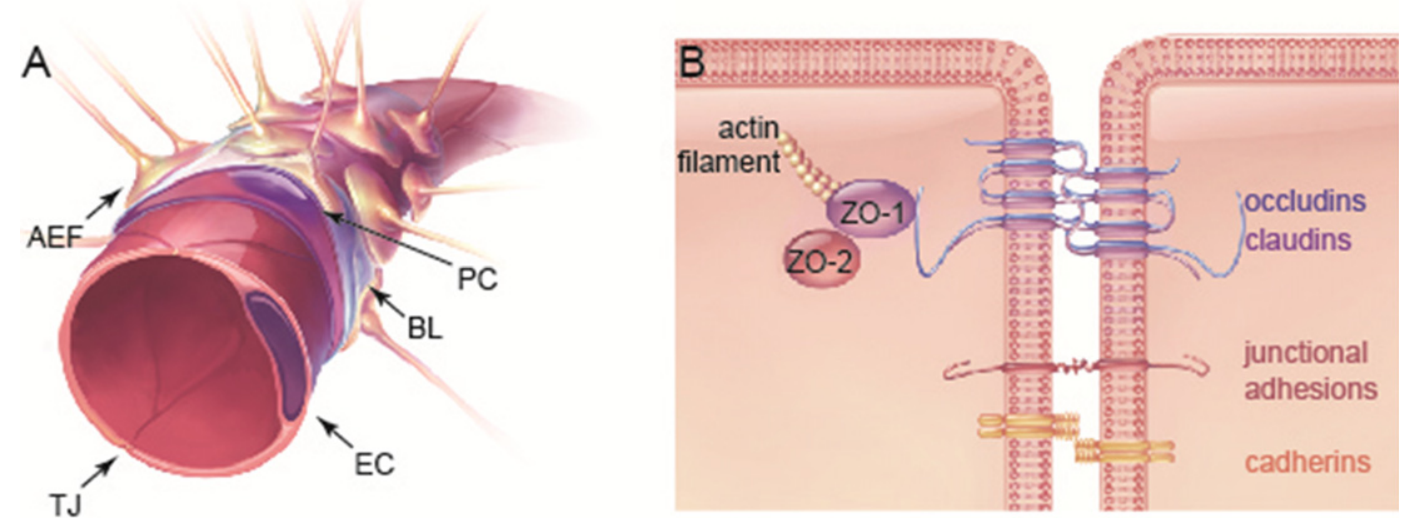

Fig. 1. The anatomy of the blood-brain barrier (BBB). (A) The BBB is comprised of astrocytic endfeet (AEF) and pericytes (PC), which surround a single layer of endothelial cells. Endothelial cells secrete extracellular matrix proteins, forming the basal lamina (BL). Endothelial cells are connected by tight junctions (TJ) that form a highly selective semi-permeable membrane, separating the brain's parenchyma from the circulatory system. (B) TJs anchor endothelial cells close together through a number of transmembrane proteins (e.g. occludin, claudins and junctional adhesion molecules). These TJ proteins interact with cytoplasmic scaffolding proteins such as zonula occludens (ZO), as well as with the actin cytoskeleton. Other integral membrane proteins and cell adhesion molecules, such as cadherins and integrins, are also found at cell-cell junctions [105]. Exercise has been shown to increase the expression of claudins, as well as the co-expression of proteins from the $\mathrm{ZO}$ and occludin family at the plasma membrane.

Rodent models have shown that short-term periods of increased physical activity are sufficient to upregulate central and peripheral factors that support the brain, and promote synaptic plasticity [4, $5,12,84-86]$ (Table 1). Nerve growth factor (Ngf), $B d n f$ and $\operatorname{Trk} B$ messenger RNA (mRNA) levels are upregulated in the hippocampus of adult rats after 3 days of free access to a running wheel, as are genes related to synaptic trafficking and signal transduction [85]. In addition, exercise promotes trophic support to the vasculature, including increased central and circulating levels of insulin-like growth factor 1 (IGF-1), which has also been shown to support neurotransmission and neuronal survival [1, 2, 56, 87-90]. The greater, systemic benefits of exercise and their relation to brain health cannot be understated, as the neuroprotective effects of exercise extend beyond the promotion of neurotrophic pathways and hippocampal neurogenesis. Voluntary wheel running has been shown to upregulate tight-junction (TJ)-associated proteins of the blood-brain barrier (BBB), which protects the brain from circulating molecules that might contribute to toxicity, inflammation, or pathogenesis [91-93]. Running has also been shown to reduce microglia activation and cytokine levels in the hippocampus of aged mice, representing another mechanism by which exercise may protect the neurovascular unit and in turn, the brain from insult [6, 94, 95]. In models of advanced aging and Alzheimer's disease $(\mathrm{AD})$, exercise reduces soluble amyloid-beta (A $\beta$ ) load and plaque formation, in part mediated by glymphatic clearance and proteolytic degradation [76, 94, 96-99]. Voluntary exercise has also been shown to delay white matter atrophy and protect cerebral vasculature in mouse models of $\mathrm{AD}$, correlating with improved performance on spatial memory tasks [100-102].

The remainder of the review will survey preclinical literature reporting the neuroprotective benefits of exercise, with special attention paid to the mechanisms by which exercise supports a healthy aging brain ${ }^{*}$. Exercise, as it pertains to these animal studies, will be defined as a greater degree of physical activity than is otherwise permitted in a control home cage either by granting free access to a running wheel, or through timed session on a treadmill. Drawing from both seminal and recent literature, the mechanisms by which exercise promotes the maintenance of $\mathrm{BBB}$ integrity, clearance of $A \beta$ peptides, and upregulation of neurotransmitters and neurotrophic factors (principally, BDNF) will be discussed.

\footnotetext{
*Please note that the specific effects of exercise on the cerebrovasculature, and on neurogenesis in animal models of $\mathrm{AD}$, are the subjects of other focused reviews found within this issue (see papers by Barnes, J.N. and Corkery, A.T.,"Exercise improves vascular function, but does this translate to the brain"; LlorensMartin, M. "Exercising new neurons to vanquish Alzheimer's Disease"). While these topics are of relevance to the discussion here and will be briefly mentioned, please refer to those articles for greater detail. In this review, general topics surrounding AD will be discussed as they pertain to the neuroprotective effect of exercise, such as exercise-facilitated clearance of $A \beta$ species.
} 
Table 1

Summary of the effects of increased physical activity on the rodent brain. The neuroprotective benefits of physical activity are noted in a variety of ages; 'age at onset' describes the age, if specified, at which the activity paradigm (whether it be acute or chronic) is commenced. (The specific effects on vasculature are not included in this table.) Please see abbreviation listed below the table

\begin{tabular}{lll}
\hline $\begin{array}{l}\text { System affected by } \\
\text { increased activity }\end{array}$ & Age at onset, Species, Sex & $\begin{array}{l}\text { 'Exercise' duration and } \\
\text { protocol }\end{array}$ \\
\hline $\begin{array}{l}\text { Blood-brain } \\
\text { barrier/Neurovascular } \\
\text { unit }\end{array}$ & $7-8$ weeks; 13 weeks, mice (male) & $\begin{array}{l}5 \text { weeks; 2 weeks } \\
\text { (respectively), VWR }\end{array}$ \\
\end{tabular}

12 weeks, mice (male)

5 weeks, VWR

adult, rats (male)

12 months, mice (female)

Glymphatic System

9 weeks, mice (female)

14-16 months, mice (male)

Neurotrophins BDNF
8 weeks, mice (male)

$2-5$ months, mice and rats
6 weeks, VWR

3 consecutive days, TR

- $30 \mathrm{~min}$, speeds increasing from $5 \mathrm{~m} / \mathrm{min}$ to $12 \mathrm{~m} / \mathrm{min}$, $0^{\circ}$ incline

6 months, VWR

5 weeks, VWR (averaged $6.7 \mathrm{~km}$ per night)

Acute session, TR

- $120 \mathrm{~min}$, at $15 \mathrm{~m} / \mathrm{min}$, with an incline of 5\%

- mice were acclimated to motorized TR running for 3 days ( $5 \mathrm{~min} /$ day, $15 \mathrm{~m} / \mathrm{min}$, $5 \%$ ); acute session began $72 \mathrm{hrs}$ after acclimatisation

3 days -4 weeks, VWR
Details

Reduced pro-inflammatory cytokines and methamphetamine-induced oxidative stress in cerebral vasculature; enhanced expression and/or co-localisation of tight junction proteins (e.g. claudin-5, occludin and ZO-1) [91, 93]

Maintained BBB integrity (enhanced expression and/or co-localisation of tight junction proteins claudin-5, occludin and ZO-1) in a mouse model of early brain metastasis; limited tumour extravasation [132]

Reduced the expression of MMP, and mitigated BBB disruption (specifically, the reduction of occludin) following middle cerebral arterial occlusion in ischemia model of stroke (TR within $24 \mathrm{hrs)} \mathrm{[130]}$ VWR from middle to early old-age attenuated age-related deterioration of neurovascular structures and vascular leakage (shown by extravasation of fibrin[ogen]), microglial activation, and decline in astrocytic ApoE; the benefit to the NVU was not seen in exercised ApoE deficient mice [92]

Glymphatic influx (as measured by fluorescent tracer) increased in awake, exercised mice as compared to mice that had been sedentary; overall tracer influx was impaired during acute running (measured in awake running mice); history of daily running increased CSF flux in widespread brain regions (primarily in hypothalamus and ventral parts of the cortex) [145] Increased expression of AQP4 on astrocytic endfeet; accelerated clearance of tracer and decreased $A \beta$ accumulation; increased dendrites, dendritic spines and postsynaptic density protein (PSD95); improved spatial memory [94]

Obese, glucose-intolerant mice (fed high-fat diet) shown to have a reduction in BDNF levels, as well as reduction in TrkB phosphorylation and CREB activation in the prefrontal cortex; $2 \mathrm{hrs}$ following an acute session of TR, levels of phosphorylated TrkB and CREB significantly elevated over sedentary mice fed the same high fat diet [347] BDNF consistently upregulated with VWR, along with proteins associated with BDNF signalling cascade; most notably increased in dentate gyrus, CA1, CA3, and CA4 of the hippocampus, and in the most caudal third of cortex (examples: $[4,5,85,86,186,190$, 348, 349]) 
Table 1

(Continued)

2 months, rats (male)

3 months, rats (male)

9 months, mice (female)

8 or 12 months, mice (male)

24 months, rats (female)

4 weeks, mice (male)

NGF

$3-4$ months, rats (male)

$3-4$ months, rats (male)
3 days, VWR (against $100 \mathrm{~g}$ resistance)

1 week, VWR (against $100 \mathrm{~g}$ resistance)

- minimum of $100 \mathrm{~m} /$ day

8 months, VWR (note: same animals underwent behavioural testing at 1 and 6-months)

5 or 8 weeks, TR

- began at $10 \mathrm{~m} / \mathrm{min}, 20 \mathrm{~min}$ for the first day and increased $10 \mathrm{~min} /$ day until $60 \mathrm{~min} /$ day reached; intensity increased to maintain $70 \%$ of animals' $\mathrm{VO}_{2}$ max; speed increased to $11 \mathrm{~m} / \mathrm{min}$ in final week 1 week habituation +4 weeks exercise regimen, TR (4 consecutive days/week) - daily regimen: warm-up ( $3 \mathrm{~min}, 2 \mathrm{~m} / \mathrm{min}$ ), two bouts of running (4-6 min, $10 \mathrm{~m} / \mathrm{min}$ ) with $1 \mathrm{~min}$ interval between

4 weeks

\section{2, 4 or 7 days, VWR}

- mice acclimated to wheel

for 3 days, then removed for

10 before testing [3, 190]

4, 7 and 28 days, VWR

- 1 week acclimation

- at least $5 \mathrm{~km} /$ day [85]
Positive correlation between exercise and hippocampal protein levels of [synaptic proteins] synapsin I and synaptophysin mRNA; synapsin I correlated with the amount of exercise (i.e. running distance); blocking TrkB (BDNF signalling) abolished the upregulation of both proteins [86] Increased BDNF, concomitant with improved performance on MWM; inhibiting the action of BDNF blocked cognitive enhancement following exercise, as well as downstream proteins involved in synaptic plasticity (CREB and synapsin I); best performance (learning and recall) associated with highest expression of BDNF and CREB mRNA levels [5]

VWR throughout middle-age (i.e. 8 months total) increased BDNF protein levels in the hippocampus of 15 month-old runners compared to age-matched controls; reduced age-related cognitive decline [48] Increased proliferation and maturation in dentate gyrus, and restored age-dependent decline in BDNF and TrkB [350]

In aging rats, shorts bouts of mild-intensity exercise increased muscle oxygen consumption by soleus and heart; lactate levels remained stable throughout 4 weeks (levels indicative of mild-moderate intensity exercise); reversed age-related spatial

learning and memory impairment; increased $B d n f$ mRNA and protein in hippocampus; increased levels of phosphorylated AKT and phosphorylated CREB protein in the hippocampus; results suggest even short bouts of exercise effective at facilitating hippocampal plasticity [82]

Increased production of $\mathrm{DBHB}$, a ketone body produced in the liver and capable of crossing the BBB, which in turn induced activity of BDNF promotors in the hippocampus via HDAC2/HDAC3 inhibition; increase in neurotransmitter release, dependent upon TrkB signalling [192]

NGF is increased in the acute/short-term phase, reported in the hippocampus at $2-3$ days and in the cortex, from $2-7$ days [3, $85,190]$ 
Table 1

(Continued)

IGF-1 adult, rats (male)

5 days, VRW (against $100 \mathrm{~g}$ resistance)

adult, rats (male)

Neurotransmitters

DA

young, rats (male)

8 weeks, mice (males)
2 weeks, TR

- 60 minutes, $17 \mathrm{~m} / \mathrm{min}$

- rats assigned to both sedentary group and exercise familiarised to treadmill

young rats: 6 months 'endurance training', TR - progressive treadmill test performed on an $18^{\circ}$ incline, correlated to peak oxygen consumption [254]

18 months, rats (male) aged rats: 12 weeks, TR [351]

2 or 4 weeks, TR

- $10 \mathrm{~m} / \mathrm{min}$ for $20-60 \mathrm{~min}$ per day (increased at an increment of $10 \mathrm{~min}$ per day), 5 days/week the first week; $60 \mathrm{~min} /$ day at the same speed, $10 \mathrm{~m} / \mathrm{min}, 5$ days/week for additional 1 or 3 weeks

- both mice assigned to exercise and sedentary groups underwent 1 week of habituation training on the treadmill $(9 \mathrm{~m} / \mathrm{min}$, $10 \mathrm{~min} /$ day for 5 days)
5 days VWR increased hippocampal levels of IGF-1, but not IGF-2; improved performance on MWM

Blocking hippocampal IGF-1 receptors during 5-day exercise period blocked the uptake of circulating IGF-1 into the hippocampus and in turn, diminished the upregulation of BDNF and its precusor, pro-BDNF; diminished rate of acquisition and abolished preference for probe quadrant in MWM; eliminated exercise-facilitated upregulation of synapsin I mRNA and protein in the hippocampus [1]

In response to exercise, IGF-1 participates in neuronal stimulation and c-fos expression in hippocampus; subcutaneous administration of IGF-1 to sedentary animals increased number of new neurons in the hippocampus; infusion of IGF-1 anti-serum blocked uptake of circulating IGF-1 into hippocampus, which abolished increase in new neurons; infusion of IGF-1 anti-serum throughout exercise period abolished both short-term and long-term survival of new cells in hippocampus [89]

Note: Physical activity produces increase in IGF-1 levels in circulation and hippocampus; uptake of circulating IGF-1 into hippocampus involved in both exercise-induced elevation in BDNF and neurogenesis; infusion of IGF-1 increases glutamate receptor subunits (particularly NR2A and NR2B) in aged mice; IGF-1 levels correlated with vascular density $[1,29$, $43,200,215,219,220]$

Increased radioligand ([3H]SP) binding to D2 receptors in the striatum and increased "synaptic coupling ratio" (defined as the "specific DA binding/DOPAC

concentration") [254]; in aged rats, regular exercise attenuated age-associated increases in DA metabolites (which can be associated oxidative stress), and increased D2 receptor binding [351]

TR regimen (meant to replicate moderate exercise in humans) completely protected against LPS-induced dopaminergic neuronal loss in the substantia nigra and attenuated motor impairment following 4 weeks of running; neuroprotection in the nigrostriatal pathway was dependent on the activation of the BDNF-TrkB signalling pathway rather than modulation of microglial activation or cytokine/chemokine levels; intrastriatal perfusion of BDNF alone was sufficient to counteract LPS-induced DA neuron loss; protection not observed after 2 weeks of running [246] 
Table 1

(Continued)

$\begin{array}{lll}3 \text { months vs 23 months, rats } & \begin{array}{l}9 \text { weeks, TR } \\ \text { (female) }\end{array} & \begin{array}{l}\text { TH mRNA, TH immunoreactivity, and TH } \\ \text { activity showed age-related decline in the } \\ \text { adjusted to approximately } \\ \text { hypothalamus; endurance training } \\ \text { co\% of their peak oxygen } \\ \text { cignificantly elevated all TH parameters in } \\ \text { speed increased as weeks } \\ \text { progressed, and differed for }\end{array} \\ & \begin{array}{l}\text { the hypothalamus of old animals }(p<0.05), \\ \text { but there was no significant change in young } \\ \text { animals following training [259] }\end{array}\end{array}$
each age group)

Note: DA neurotransmission has been shown to increase BDNF production, as well as surface expression and phosphorylation of TrkB (in vitro and in vivo); TrkB signalling shown to increase expression of D1 and D3 receptors (in vitro and in vivo) [246-248, 259]

$\mathrm{CA} 3, \mathrm{CA} 4$ and detate gyrus; modest increase in BDNF mRNA with antidepressant, tranylcypromine, CA3 and dentate gyrus only; $\beta$-adrenergic receptor blockade significantly blunted BDNF mRNA elevations in response to exercise, and inhibited modest elevations resulting from antidepressant treatment in CA3 [189]

young, rats (sex not specified) - age not specified, $146+/-2 \mathrm{~g}$ at start of study

adult, rats (male)

- age not specified, $220 \mathrm{~g}$ on arrival

adult,rats (male)

- age not specified, $300+/-15 \mathrm{~g}$ at start of study
5 days/week, 2 weeks (TR) (1 hour, $25 \mathrm{~m} / \mathrm{min}$, $3 \%$ slope)

- workload corresponded to $70 \% \mathrm{VO}_{2} \max$ - 4 day break, in which microdialysis probe implanted + recovery - Acute session of 1 or $2 \mathrm{hrs}$ 5 days, VWR (against $100 \mathrm{~g}$ resistance)

Acute session, $120 \mathrm{~min}, \mathrm{TR}$ - trained 6- 7 times prior to experiment day, gradually accustomed to run at $25 \mathrm{~m} / \mathrm{min}$; 2 days before experimentation, ran $30 \mathrm{~min}$ at a speed of $25 \mathrm{~m} / \mathrm{min}$

6 days, VWR

6 weeks vs 3 months vs 1 year, mice (female)

- Tph2 -/- and controls
Increased levels of NA centrally and peripherally following 1 and $2 \mathrm{hr}$ exercise sessions; the peak of NA concentration in the cortex is higher with 2 hours of exercise, and levels remain elevated for longer periods as compared to a 1-hour session [266] (see also [265])

Blocking the $\beta$-adrenergic receptors with propranolol ( $\beta$-blocker that crosses the BBB) but not nadolol (peripherally acting, does not cross the BBB) before each of five consecutive nights of exercise reversed the exercise-induced improvement in learning and memory in rat [271] (see also [270]) Hippocampal and cortical 5-HT levels significantly increased by $90 \mathrm{~min}$ of intense aerobic exercise (collected by microdialysis); maximal levels in the cortex, $30 \mathrm{~min}$ after exercise cessation and in the hippocampus, $60 \mathrm{~min}$ after cessation; hippocampal levels remained elevated at least 90 minutes after cessation; cortical 5-HT levels rapidly decrease when hippocampal levels still maximal [352] Tph2-deficient mice have normal baseline hippocampal neurogenesis but impaired proliferation in response to increased physical activity; serotonergic deficits results in alterations in Sox2-positive precusor cells; serotonergic signalling required for proproliferative effect on physical activity, in young and aged animals [292] (see also: [293]) 
Table 1

(Continued)

Glutamate $28-40$ days, mice (sex not specified)

3 months, rats (male)

3 months, rats (male)

GABA

5-6 weeks, mice (male)

5-6 weeks, mice (male)

40 days, VWR
3, 7 or 28 days, VWR (against $100 \mathrm{~g}$ resistance) - VWR followed 1 week habituation at least $5 \mathrm{~km} /$ day

- Similar results seen with TR, $3,7,15$ or 30 days (40 minutes daily, $10 \mathrm{~m} / \mathrm{min}$ )

3 or 7 days, VWR at least $5 \mathrm{~km} /$ day (against $100 \mathrm{~g}$ resistance)

10 days, VWR
Synaptic plasticity in dentate gyrus examined in vitro: LTP significantly greater in slices prepared from runners than control animals; LTP significantly reduced by NR2B subunit antagonists in both groups; LTP blocked by an antagonist with higher affinity for NR2A (NVP-AAM077) in running groups, with only slight depression in controls; NVP-AAM077 completely blocked LTD in runners but not controls [236] Increased synaptic glutamate receptors (mRNA and/or protein levels) in several brain regions including, but not limited to, the hippocampus, motor cortex, sensory cortex, and striatum; mRNA expression of NMDAR subunits modulated in hippocampus after 3 days of VMR (NR2A and NR2B); AMPA receptors modulated after 10 days of VWR or 30 days of TR [85, 186, 353]

Blocking NMDAR (MK-801, delivered unilaterally by microsphere into hippocampus) was sufficient to fully abrogate exercise-induced increases in Bdnf, $\operatorname{TrkB}, C R E B$, and Synapsin I, suggesting an interaction between BDNF and glutamate signalling may be necessary for increased transcription of genes modulating synaptic plasticity [4]

GABAergic transmission excitatory in the first two weeks and becomes inhibitory as granule cells mature and integrate into networks; involved in initial integration of adult-born neurons [354]

Young, 1-week old progenitor cells receive input from inhibitory GABAergic interneurons and cholinergic input from the septum, as well as multiple intra-hippocampal glutamatergic cells types, all of which have been implicated in the maturation and integration of new neurons [296]; exercise enhances new dentate granule cell number, arborization and morphological complexity but only NMDA-mediated glutamatergic inputs shown to be modified by running [296] Electrophysiological recordings from slices taken from exercised mice suggest that alternations to glutamatergic inputs, rather than GABAergic inputs, are predominately responsible for increased morphological complexity in new neurons [296] In new neurons, ratio of interneuron inputs to new neurons was reduced, but GABAergic inhibitory synaptic transmission was not changed by running; in mature granular cells in the outer molecular layer, synaptic inhibition was strongly increased, (possibly due to interneuron sprouting of axonal collaterals onto these cells) [297] 
Table 1

(Continued)

young, rats (males),

- age not specified, $140-160 \mathrm{~g}$

on arrival

6 weeks, mice (male)

adult, rats (male)

3-4 months, rats (male)

26-29 months, 'healthy aged' rats (male)

adult, mice (male)
4 weeks, VWR

- ran 5-9 km per night

- began running 1 week after arrival

6 weeks

5 minutes, walking on treadmill $\left(2.3 \mathrm{~m} / \mathrm{min}, 0^{\circ}\right.$ incline)

30 seconds or 3 minutes, walking on treadmill $(4 \mathrm{~cm} / \mathrm{s}$, $0^{\circ}$ incline)

30 seconds or 3 minutes, walking on treadmill $(2,4$, or $8 \mathrm{~cm} / \mathrm{s}, 0^{\circ}$ incline)

15 consecutive days, TR (30 $\mathrm{min}, 5 \mathrm{~m} / \mathrm{min}, 0^{\circ}$ incline)
Gene expression of various $\mathrm{GABA}_{\mathrm{A}}$ receptor subunits as well as the GABA-synthesising enzyme glutamic acid decarboxylase-67 (GAD67) altered in the forebrain of runners (in situ hybridisation histochemistry): region-specific decreases in mRNA expression of $\alpha 2, \beta 3$ and $\gamma 2 \mathrm{GABA}_{\mathrm{A}} \mathrm{R}$ subunits and region-specific increases in $\beta 1$ subunit; $\alpha 5$ and $\delta$ subunits showed differential increases in mRNA expression levels; GAD67 mRNA increased in many forebrain regions, including all hippocampal cell layers, peri-paraventricular nucleus, bed nucleus stria terminalis, nucleus accumbens core and motor cortex [241]

During cold water swim stress, increased expression of the protein products of the immediate early genes c-fos and arc in granular neurons (new and mature) of sedentary mice but not runners Runners showed enhanced local inhibitory mechanisms in the hippocampus during stress test: increased in stress-induced activation of hippocampal interneurons, expression of vesicular GABA transporter, and extracellular GABA release [355] Increased ACh (as well as NA and 5-HT) levels in cerebral cortex, sampled from freely-behaving animals by microdialysis [226, 227, 356]

Increased ACh in hippocampus; increased regional blood flow; abolished by AChR antagonists; various degrees of physical activity shown to elevate ACh levels in cortex and hippocampus [357]

- Similarly, increased ACh release in hippocampus of aged rats (likely cholinergic fibres that originate in the septal complex of forebrain and project to hippocampus); increased regional blood flow [237]. In scopolamine-treated mice, a pharmacological model of amnesia, treadmill exercise ameliorated short-term memory impairment, suppressed AChE expression, and enhanced angiogenesis [239] Note: An increased concentration of ACh in the hippocampus supports the generation of theta oscillations, which serves to facilitate synaptic plasticity, learning and memory [240, 324, 325]. 
Table 1

(Continued)

Neurogenesis 3 weeks, mice (female)

40 days in enriched environment (tunnels, toys and running wheel; 3 mice per cage) $\longrightarrow$ second group survived 68 days total (after 40 days in enriched or control environments, tested on MWM for 5 consecutive days, then returned to assigned environments for an additional 23 days)

3 months, mice (female)

3 months, mice (female)

3 months vs 19 months, mice (male)

3 months $v s, 12$ and 24 months, mice (male)
12 days, 40 days, VWR (vs other conditions in enriched environments)

2 months or 4 months, VWR $1+$ months

45 days, VWR

6 months VWR (young mice) vs 10 days VWR (aged)
Housing in enriched environments, which included running wheels, induced neurogenesis: when mice were sacrificed 1 day after final BrdU injection (daily, 12 days), no significant difference between two groups suggesting little influence on proliferative activity of progenitor cells in dentate gyrus; when mice sacrificed 4 weeks after last injection, a significantly higher number of BrdU+ cells in the dentate gyrus of mice living in enriched environments, suggesting a survival-promoting effect on proliferating neuronal precursors; studies in mice of an alternative background $(129 / \mathrm{SvJ}$ rather than C57BL/6) did show a significant increase in the number of progenitor cells under similar conditions [72, 73]

Running is sufficient to increase hippocampal neurogenesis: an increase in both proliferating cells (measured 1 day after last BrdU injection, injected daily for 12 days) as well surviving neurons, after an additional 4 weeks of VWR, seen in running group and enriched environment groups only LTP and spatial learning in mice [56] Improved performance on MWM, increased cell proliferation (as measured by BrdU+ cells) and enhanced LTP in the dentate gyrus. Faster acquisition and better retention on MWM than sedentary age-matched controls; age-related decline in neurogenesis ameliorated (compared to young and aged controls); fine morphology of new neurons did not differ between young and aged runners; perimeter and surface area of blood vessel increased in young runners but not aged mice; angiogenesis was not a rate-limiting factor for neurogenesis (angiogenesis not increased in this study, although reported to be increase in motor cortex, cerebellum and hippocampus following running in other studies) [57] Chronic (i.e. long-term) running starting at 3 months of age attenuated age-dependent decline in precursor cell proliferation measured at 9 months; short-term running reduced age-related decline in cell proliferation at 12 and 24 months, but did not return net neurogenesis to 'young levels' in this study [41]

ACh - acetylcholine; AChE - acetylcholinesterase; AKT - Protein kinase B; BDNF - brain derived neurotrophic factor; BrdU - bromodeoxyuridine; CA - cornu Ammonis (i.e. hippocampal subfield); CREB - cAMP response element-binding protein; CSF - cerebrospinal fluid; DA - dopamine; DCX - doublecortin; DOPAC - 3,4-Dihydroxyphenylacetic acid (a dopamine metabolite); DRN - dorsal raphe nucleus; HDAC - histone deacetylase; 5-HT - serotonin; IGF-1 - insulin growth factor 1; LPS - Lipopolysaccharide; LTD - long-term depression; LTP - long-term potentiation; MMP - matrix metalloproteinases; MWM - Morris Water Maze; NA - noradrenaline; NMDAR - N-methyl-D-aspartate receptor; NR2A/2B - NMDAR subunits 2A and 2B; NGF - neurotrophic growth factor; TR - treadmill running (controlled for duration and speed); VWR - voluntary wheel running (animals are freely behaving); ZO-1 - zonula occludens 1 . 


\section{EXERCISE MAINTAINS THE BBB AND SUPPORTS THE NEUROVASCULAR UNIT}

\section{The $B B B$ in health and disease}

The BBB is a highly selective semi-permeable membrane at the interface between the circulatory system and brain parenchyma, formed of specialised endothelial cells that compose the walls of all cerebral blood vessels (Fig. 1). The endothelial cells are in turn encased by a layer of pericytes, astrocytic endfoot processes and neurons. Together, these cells comprise the neurovascular unit, communicating with one another to tightly regulate cerebral blood-flow and maintain a homeostatic chemical environment within the brain [103, 104].

TJs between adjacent endothelial cells set the brain's vasculature apart from most other blood vessels in the body. They are primarily formed by transmembrane proteins (occludins, claudins, and junctional adhesion molecules) that interact with cytoplasmic scaffolding proteins (i.e. zonula occludens $[\mathrm{ZO}]$ proteins and the actin cytoskeleton), and other membrane-associated proteins (i.e. kinases, GTPases, and G proteins) [105-108]. The integrity of TJs is critical to forming the protective barrier of the BBB, which selectively limits the passage of molecules between the circulating blood and the extracellular fluid in the brain [104, 108] (Fig. 1). Both meta-analyses of human subjects and animal models have revealed an association between normal aging and BBB deterioration [109-111]. Injury or disease may contribute to BBB dysfunction, and can be associated with the presence inflammatory markers; if this state is prolonged or persistent, a compromised BBB can permit the extravasation of circulating molecules, including those that are neurotoxic [112-120].

\section{Exercise protects the neurovascular unit}

In animal models of aging, habitual long-term (or, 'chronic') aerobic activity has been shown to protect the neurovascular unit and maintain the integrity of the BBB. Soto and colleagues demonstrated that daily voluntary running (at an average of $3 \mathrm{~km}$ per night) from midlife (12 months of age) to early old age (18 months of age) reduced age-related neurovascular dysfunction in mice, leading to a 'younger-like' brain. Long-term voluntary running, representing an 'active' lifestyle, was shown to preserve the basement membrane of the neurovascular unit and to prevent the neurovascular deterioration and leakage observed in sedentary mice at 18 months: a significant reduction in fibrin levels was found in aged runners compared to sedentary age-matched controls, with levels more closely resembling those seen in 12-month-old mice [92]. Aged runners also showed higher levels and coverage of cortical and hippocampal pericytes, as well as a reduction in astrocytic and microglial activation. Notably, running prevented an age-related decline in astrocytic ApoE, an anti-inflammatory protein important in cerebrovascular maintenance and pericytic signalling [92, 121, 122]. Running was not, however, associated with a significant effect in aging ApoE-deficient mice, suggesting that ApoE may partially mediate the beneficial effect of exercise on the neurovascular unit [92]. As allelic variations in $A P O E$ are associated with decreased longevity and the development of familial forms of AD [123, 124], this is a relevant observation for translational research. It is possible that exercise may offer greater BBB protection in some individuals than others, however this would not diminish the other neuroprotective and health benefits promoted by exercise. For instance, voluntary running and treadmill training were also shown to decrease microglial and astrocytic activation in aged rodents (with some sex- and regionspecific effects), which may aid in the protection of the neurovascular unit from damage $[90,94,95]$.

\section{Exercise maintains the $B B B$}

Animal models of disease and toxicity, with injury to the BBB, can provide additional insight into the benefits of an active lifestyle. Spontaneously hypertensive rats (SHR) have been shown to have greater BBB permeability and increased angiotensin II (Ang II) in the brain parynchema (both locally-produced and circulating), which not only alters neurovascular coupling and dysregulates cerebral perfusion, but permits the extravasation of circulating inflammatory cells [125]. In a recent study, the maximal aerobic capacities of individual SHR and Wistar Koyoto (control) rats were determined at the start of experimentation, and used to ensure rats with identical capacities were allocated to both the trained and sedentary groups [125]. Rats in the exercise group then underwent aerobic treadmill exercise for 2 months, set to $50-60 \%$ of their own maximal exercise capacity (performed 5 days/week, 1 hour/day). The marked fluorescein isothiocyanate dextran (FITC, $10 \mathrm{kD}$ ) leakage seen in the autonomic areas of the 
sedentary SHR group was significantly diminished after just 2 weeks of treadmill training. Although regional Ang II content was not directly measured, authors of the study suggest that regular treadmill running may reduce Ang II content in autonomic areas, as simultaneous intracerebroventricular Ang II infusion abrogated training effects on both FITC leakage and microglia activation. This interpretation is supported by studies demonstrating that pharmacological blockage of the Ang II receptor, AT1, reduced BBB permeability in autonomic regions of hypertensive rats; AT1 receptor blockade has also been shown to reduce BBB permeability in the hippocampus and cortex [125-129].

Physical activity may support or strengthen the BBB by modulating the expression of TJ-proteins, and in the same way, aid in its recovery following injury. Started 24 hours following middle cerebral artery occlusion in rats, short-term treadmill running (30 minutes per day for 3 days) attenuated an ischemia-induced reduction in occludin, reduced disruption of the BBB, and diminished expression of matrix metalloproteinases (MMPs) [130]. Similar results were observed in rats undergoing a pre-ischemia treadmill program (30 min per day, 5 days/week, 3 weeks) [131]. Rats that had been exercised prior to ischema showed reduced infarction size and reduced Evan's Blue extravasation; moreover, exercised rats show enhanced expression of proteins associated with the basal lamina such as collagen IV, a major component of the basement membrane of cerebral microvessel. In a murine model of brain metastasis, mice that ran for 5 weeks prior to tumor cell infusion showed enhanced expression of claudin-5 and occludin [132]. Furthermore, while tumor cells target ZO-1 to increase BBB permeability, prior running resulted in a reduction in tumor cell extravasation at both 48-hour and 3-week time points.

As an interventional strategy, exercise was reported to be protective in a mouse model of drug-induced damage to the BBB. Methamphetamine (METH) exposure has been shown to reduce the expression of claudin-5, occludin and $\mathrm{ZO}-1$, and disrupt the co-localisation of occludin and ZO-1 in the plasma membrane [91, 93]. Two weeks of voluntary running following exposure to METH enhanced the expression of TJ proteins, stabilised the BBB, and attenuated a METH-induced increase in systemic pro-inflammatory cytokines. Furthermore, exercise significantly increased the number cells co-labelled with bromodeoxyuridine (BrdU) and NeuN, a neuronal nuclear antigen, compared to sedentary mice following METH administration. This demonstrated that, in addition to its effects on the BBB, exercise can attenuated the suppression of neurogenesis associated with METH-toxicity [91, 93].

Together, these studies indicate that engagement in regular sessions of aerobic physical activity has the capacity to strengthen the BBB by upregulating TJassociated proteins, and in this way, protects the brain from circulating insults. Reductions in BBB permeability were reported whether exercise programs was administered prior to or following an injury (such as that imposed by ischemia or drug toxicity), with a rapid increase in TJ proteins observed after just 3-14 days of scheduled treadmill running or voluntary wheel running (respectively) [91, 130].

\section{EXERCISE PROMOTES GLYMPHATIC CLEARANCE IN AGED MICE}

The glymphatic system is defined by a space between the vessel basement membrane and glial limitans formed around pre- and post-capillary vessels, in which the cerebrospinal fluid exchanges with interstitial fluid. The astrocytic endfeet that line the paravascular space express astrocyte water channel aquaporin 4 (AQP4), a bidirectional channel believed to facilitate influx and efflux of molecules between these fluids. Glympathic influx delivers glucose and signalling molecules to the cerebrospinal fluid; efflux, conversely, has an important role in the clearance of waste products and compounds in the interstitial fluid (including $\mathrm{A} \beta$ and tau), and eventually drains into the subarachnoid space and cervical lymph nodes [133]. Glymphatic activity has been found to be increased in sleep, and decreased in traumatic brain injury, stroke, and subarachnoid hemorrhage [134-136]. In addition, glymphatic transport is reduced with age and certain diseases, such as small vessel disease [134, 137-141]. Furthermore, glymphatic dysfunction has implications in disorders characterised by accumulation of abnormal proteins, such as AD. For example, the accumulation of $A \beta_{40}$ and cerebral amyloid angiopathy (CAA) can result in $A \beta$ deposits in the basement membrane drainage pathways, in turn impeding the glymphatic elimination of $A \beta$ and interstitial fluid from the brain [141-143]. Since the glymphatic system is believed to be under immune surveillance by blood-borne macrophage and T cells, it serves as an important bridge between the brain and rest of the body [138]. Nonetheless, it is worth noting that our understanding of the mechanisms of the glymphatic system, or a similar sort of fluid filtration system, still requires refinement [144]. 
In middle-aged mice, 6 weeks of voluntary running has been shown to accelerate efficiency of glymphatic clearance, assessed using intracisternal injections of a paravascular tracer. The expression of AQP4 was increased in runners, as was its distribution to astrocytic endfeet, while BBB permeability was unaltered [94, 145]. Running mice also showed reduced intraneuronal $A \beta_{1-40}$ accumulation in the cortex as well as reduced $A \beta_{1-42}$ deposition outward of vessel. Furthermore, access to a voluntary wheel running reduced activation of astrocytes and microglial [94], an important observation given recent focus on the relationship between the BBB and a glymphatic system [133, 139, 144]. Although research pertaining to glymphatic clearance of neurotoxins is relatively young, these studies suggest that such a system may participate in the neuroprotective benefits of increased physical activity.

\section{EXERCISE FACILITATES CLEARANCE AND DEGRADATION OF SOLUBLE A $\beta$}

Regular, long-term aerobic activity that commences in the pre-plaque stage has been shown to inhibit hippocampal and cortical $A \beta$ deposition in several mouse models [76, 99, 146, 147]. TgCRND8 mice who underwent voluntary running for 3-5 months have shown reduced $A \beta$ load, and CAA pathology [76, 99, 146]. Similar reductions in the number of plaques have been reported in Tg2576 mice $[98,148]$. Ten weeks to 5 months of treadmill training in APP/PS1 trangenic mice (beginning at 3 months of age) also inhibited the expression of AD-like pathology, including robust reductions in both $A \beta$ deposition and tau phosphorylation [147, 149, 150]. Recent work has shown that housing animals in enriched environments (equipped with activity wheels) is effective at ameliorating memory deficits related to $A \beta$ toxicity, as induced by intra-hippocampus infusions of $A \beta_{25-35}$ [151]. When housed in an enriched environment prior to the introduction of $A \beta$, which provides both voluntary access to physical activity and cognitive stimulation, rats showed improved performance on short- and long-term novel object recognition challenges. Exercised rats also presented lower lipid peroxidation, showing that physical activity may protect against $\mathrm{A} \beta$-induced cellular damage [151].

Recent studies have focused on the mechanisms by which exercise attenuates the build-up of $A \beta$ in the brain [96, 97, 101, 150, 152-154]. The support- ive role of exercise in glymphatic clearance of toxic molecules, including $A \beta$, was described in the previous section. A 2017 study showed that exercise can also decrease $A \beta$ production in NSE/APPsw mice, by biasing the processing of amyloid precursor protein (APP) toward a non-amyloidogenic pathway [96]. This effect was mediated by enhancement of the sirtuin-1 pathway. Authors demonstrated that treadmill running reduced levels of the $\beta$-site APP cleaving enzyme (BACE-1), which is responsible for the first cleavage step in the transformation of APP into A $\beta$. In addition, exercise enhanced expression of a disintegrin and metalloproteinase domain-containing protein 10 (ADAM-10), which cleaves APP in a nonamyloidogenic pathway [96]. These changes correlated with reductions in cortical $A \beta_{40}$ and $A \beta_{42}$, reduced cortical markers of cell death, and improved performance on the Morris water maze [96].

Moore and colleagues used $\operatorname{Tg} 2576$ mice, which normally develop amyloid plaques around 9 months of age, to determine if the preventative effects of exercise are 'dose dependent' using two different exercise regimens [97]. Animals engaged in either low-intensity training or high-intensity treadmill training, where soleus muscle citrate synthesis was increased by $39 \%$ and $71 \%$ relative to sedentary mice, respectively. In both in the cortex and hippocampus, treadmill training from 3 to 6 months of age reduced soluble $A \beta_{40}$ and $A \beta_{42}$ in an exercise-training dose-dependent manner. Moreover, there was an upregulation of 5 proteins involved in $A \beta$ clearance (or efflux) and degradation: neprilysin, insulindegrading enzyme (IDE), matrix metallopeptidase 9 (MMP9), low-density lipoprotein-related receptor 1 (LRP1) and heat-shock protein 70 (HSP70). Upregulation of these proteins was also dependent on training intensity [97]. The intensity-dependent reduction of $\mathrm{A} \beta$ is an interesting observation, as it is consistent with the positive correlation between duration and/or intensity of exercise and BDNF production noted in both humans and animals.

The studies described here demonstrate that exercise protects against $A \beta$ build-up when commenced in a pre-plaque period and in this way, it can be considered in the context of a greater preventative strategy. In genetic animal models, the effects on $A \beta$ load could not be recapitulated when exercise was commenced after plaque onset [155], however studies of $\mathrm{AD}$ patients in nursing homes have reported positive cognitive effects on cognition and behaviour that can likely be attributed to some of the other factors positively affected by exercise [22, 156, 157]. 


\section{EXERCISE PRODUCES A RAPID UPREGULATION OF NEUROTROPHIC FACTORS}

\section{$B D N F$}

Growth and neurotrophic factors, as well as hormones produced both in the brain and periphery, are essential for the growth and maturation, survival, and function of cells in the brain [1,20,89, 158-160]. BDNF, the most widely distributed neurotrophin in the brain, participates in neurogenesis, synaptogenesis and dendritogenesis, and also initiates signalling cascades that upregulate transcription of pro-survival genes [55, 161-168]. In addition, BDNF-mediated pathways promote the induction of hippocampal long-term potentiation (LTP) [161, 169]. Conditional TrkB knockout mice show age and region-specific reductions in spine density as well as altered spine morphologies in the hippocampus, which are linked to impaired LTP [38, 45]. Moreover, disruption of hippocampal BDNF/TrkB signalling - genetical or pharmacological - has been shown to result in a variety of memory deficits in rodent models, demonstrating the functional relationship between BDNF and cognition [5, 153, 159, 169-172]. In humans, BDNF and full-length TrkB are reduced with age and in early stages of AD, where decreased BDNF/TrkB signalling has associated with both cognitive decline and the presence of oligomeric $A \beta_{1-42}[35,37,173-178]$. Reductions in BDNF and full-length TrkB have also been described in aging rodents, and correlate to AD-like pathology, aberrant spine morphology, and impaired signalling pathways [42, 45, 174, 179].

BDNF is known to be elevated by physical activity. In healthy human participants, BDNF has been reported to be elevated in blood serum both after one acute session of moderate to intense (anaerobic) exercise as well as by chronic aerobic training, such as 5 weeks of training on a stationary bike, 3 times per week, where workload was gradually increased to maintain $60 \%$ of maximal oxygen consumption $\left(\mathrm{VO}_{2}\right.$ $\max$ ) for 60 minutes $[8,9,180,181]$. However, metaanalyses revealed that regular exercise augments the effect of any single exercise session on serum levels of BDNF, and that only aerobic exercise had an effect on resting BDNF levels [182, 183]. And while BDNF is robustly up-regulated in contracting muscle fibres, analyses of the arterial-to-internal jugular venous difference in plasma BDNF levels suggest that neurotrophin produced and released from the brain contributes $70-80 \%$ of circulating levels following 4 hours of aerobic exercise [9].

As in humans, increased physical activity in rodents elicits a rapid elevation in the transcription and translation of BDNF and TrkB in the hippocampus. Indeed, a positive correlation between levels of hippocampal BDNF and the activation of gene transcription pathways has been described after only 6 hours of voluntary running in mice (during which they ran approximately $6 \mathrm{~km}$ ), mimicking an acute session of exercise in humans [184]. (Note: Six days earlier, mice had been exposed to the wheel for 48 hours to habituate them to the wheel). In rats, the upregulation of $B d n f$ mRNA has been well-characterised after 2 days of voluntary wheel running and $\operatorname{TrkB}$, after 7 days [3-5, 85, 185-190]. The upregulation of $B d n f$ mRNA is region-specific, demonstrated by in situ hybridisation in rats aged 3 and 22 months; changes are most notable in the dentate gyrus, CA1, CA3, and CA4 of the hippocampus, and in the most caudal third of cortex, though less robust in the aged cohort $[188,191]$.

The uptake of peripherally circulating factors, released in greater quantities during exercise, contribute to central increases in BDNF production [1, 85, 192] (Fig. 3). Blocking hippocampal uptake of circulating IGF-1 or the IGF-1 receptor significantly blunts the exercise-induced increase in $B d n f$ mRNA and protein, as well as that of it precursor protein $[1,75,193]$. Recently, $\beta$-hydroxybutyrate (DBHB), a BBB-permeable ketone body produced in the liver, has been shown to accumulate and stimulate production of BDNF in the hippocampus following exercise [192]. There, it acts as both an energy source and an inhibitor of class I histone deacetylases to enhance BDNF expression. It has also been shown to attenuate stress-induced behavioural and hippocampal neuroinflammation [194]. Notably, exercise-associated increases of hippocampal BDNF are replicated by direct ventricular application of DBHB [192]. And while there is an age-related decline in the transport of DBHB into the brain, studies have suggested that exercise has the capacity to regulate the expression of the monocarboxylate transporters that mediate its passage [195-199]. Together, these studies demonstrate that the production of BDNF, and in turn its effects upon neuronal survival/plasticity, can be modulated by circulating factors. As many of these factors decline with age, exercise may serve to enhance their presence and, in turn, their ability to reach the brain [29, 43, 192, 198, 200].

Notably, prolonged periods of exercise (i.e. 3 weeks to 8 months of voluntary running) produce 


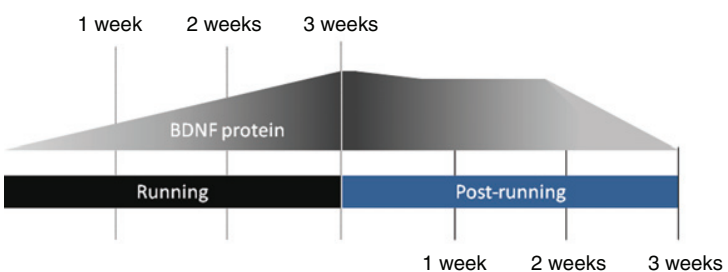

Fig. 2. Regular physical activity produces a progressive and sustained increase in the expression of brain-derived neurotrophic factor (BDNF). Elevation of intraparenchymal BDNF protein levels are graded with the duration (or total period) of regular sessions of physical activity, with profound mRNA increases detectable starting from 2-3 days. Cessation of exercise is followed by a gradual decline of BDNF protein level though it has been shown to remain significantly higher than baseline levels for up to 2 weeks. Notably, a return to exercise results in a rapid reinstatement of elevated protein levels, more quickly than is typical of exercise-naïve rodents [201, 202]

progressive elevations of $B d n f$ transcription and protein translation in rodents [54, 57, 185, 201-203] (Fig. 2). In one experiment, mice who ran daily for $2,4,7,14,28$ and 90 days showed a progressive increase in BDNF protein levels in the hippocampus; the results were mirrored in mice who ran on alternating days rather than daily [201, 202]. Furthermore, protein levels have been shown to remain elevated over control levels beyond the period of exercise: following a 3 week period of daily voluntary running, hippocampal levels of BDNF were reported to be elevated for at least 2 weeks [201]. Moreover, a history of exercise has also been describe as a "molecular primer" for BDNF production, where a brief exposure to running can rapidly increase hippocampal levels following a period of rest [202]. For example, in rats returning to exercise after a week-long sedentary period, 2 days of running produced BDNF levels comparable to those requiring several weeks of running in mice who were exercise naïve. The potentiation of BDNF upregulation was comparable between animals that ran daily and those who ran on alternate days (though the post-exercise decay was shorter in the latter group), suggesting that alternative exercise regimens can provide similar benefits [202]. Recent studies have addressed whether workload, in the absence of added stress, leads to greater $B d n f$ transcription by comparing rats assigned to 7 days of no exercise, voluntary running, or voluntary running on a loaded 'resistance' wheel [204]. One week of running on a loaded wheel demonstrated a positive correlation between BDNF production and "workload", as measured by energy expenditures calculated by distance, resistance and body weight; no change was seen in TrkB between groups. These animal studies are valuable as they are consistent with observations in human studies of acute high-intensity exercise and aerobic exercise, and establish similarities between species in the required 'work' to produced elevated BDNF levels. More specifically, they demonstrate a variety of exercise regimens are capable of producing increased BDNF levels, on a similar time-course, in both rodents and humans, and that regular exercise is required for prolonged elevations. This provides good rationale for using rodents to establish the molecular effectors downstream of activity-induced elevations in BDNF.

\section{Neural growth factor}

While some studies have reported upregulation of $N g f$ mRNA after physical activity, its role in supporting exercise-mediated neurogenesis and neuroprotection is less well-defined. A study of middle cerebral artery stroke in rats showed that forced treadmill running for 12 weeks (but not 4 or 8 weeks) increased cortical $\mathrm{Ngf}$ expression and reduced the volume of infarction [205]. In contrast, when mice were exposed to 10 days of treadmill 'rehabilitation' intervention beginning 4 days after stroke induction, NGF/Trk-A signally was not elevated; instead, $\mathrm{BDNF} /$ TrkB signalling was increased and associated with repair processes [206]. Previously, analyses had shown that voluntary running mediated only a transient increase in $N g f$ expression in the hippocampus, with levels elevated in after 3 days but not beyond [85], though it remained elevated in the caudal cortex when measured after 7 days of running [190]. Topographical differences within the hippocampus were found with in situ hybridisation, with a modest but significant increase in $N g f$ mRNA after 7 days of running in the dentate gyrus and CA4 regions, as well as in the caudal cortex [190]. The local and temporal differences in NGF versus BDNF upregulation in response to exercise suggests that they likely play different roles in the neuroprotection of the aging brain.

\section{Insulin-like growth factor-1}

The protective effects of exercise also involves trophic factors that are produced peripherally, such as such as IGF-1 and vascular endothelial growth factor (VEGF) [1, 2, 16, 147, 207-209]. Peripheral factors can aid in neuroprotection by supporting angiogenesis and modulation of energy metabolism [1, 6, 89, $180,181,210]$. Stimulated by circulating growth hor- 
Systemic circulation

Peripherally produced factors

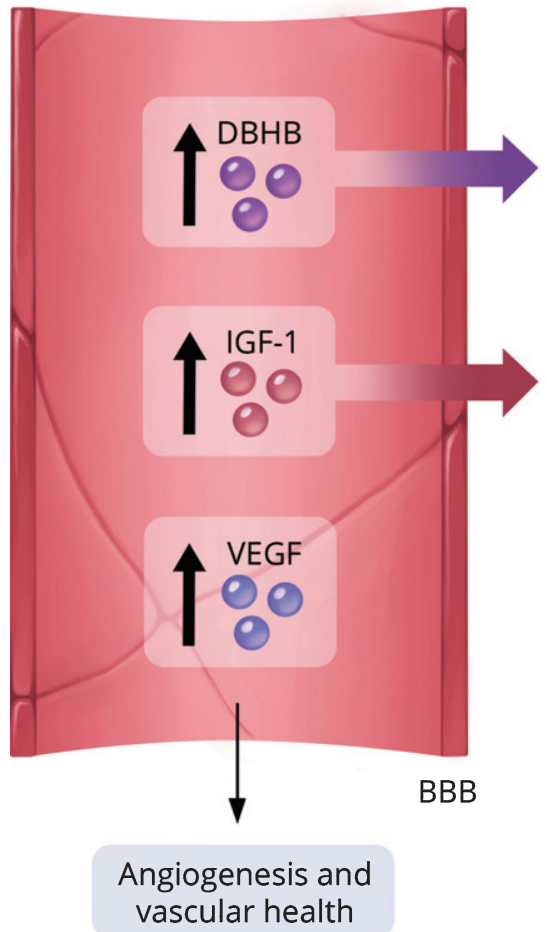

Intraparenchyma

Centrally produced factors

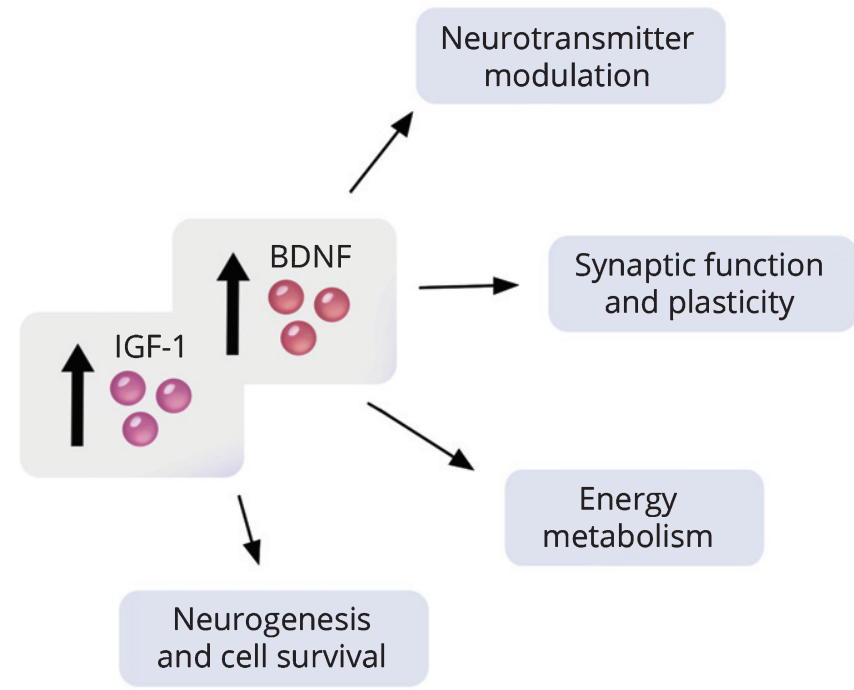

Fig. 3. Both circulating and central factors participate in exercise-facilitated protection of the brain. Exercise can increase both peripheral and central factors that co-operate in sustaining brain health. Systemic circulating factors that are elevated by exercise include betahydroxybutyrate (DBHB), vascular epithelial growth factor (VEGF) and insulin growth factor-1 (IGF-1). Some circulating factors, such as DBHB and IGF-1, are capable of crossing the blood-brain barrier (BBB) and may contribute to the upregulation of BDNF [16, 19, 20, 192, 209].

mone $(\mathrm{GH})$, IGF-1 is produced by the liver before being released into the circulatory system [211]. It is also derived and stored in peripheral tissue, such as skeletal muscle, from which it can be rapidly released; transient increases in circulating IGF-1 following acute, high-intensity (anaerobic) exercise are believed to be muscle-derived, and are independent of GH levels [29, 193, 212-214]. However, studies have suggested that muscle-derived IGF-1 may also be an important source of circulating levels following periods of more moderate, regular exercise [193, 213, 215].

Circulating IGF-1 is BBB-permeable and thus able to reach the brain parenchyma. It is widely expressed centrally, where it is believed to modulate and support both cells and cerebrovasculature. In the brain, glial cells are known to have a role in mediating neuroprotective properties of IGF-1 and have been particularly well-studied in models of hypoxia, where IGF-1 treatment reduced oligodendrocyte loss and neuronal death [216-219]. Importantly, both GH and
IGF-1 levels decline with age, coincident with neurological and vascular changes [28, 29, 43, 211, 220]. In 32 month-old rats, 2-4 weeks of IGF-1 treatment enhanced both neurogenesis and vascular density and ameliorated age-related declines in the performance of tasks involving working memory (e.g. repeated acquisition task and novel object recognition) $[29,88,200,220]$. In 28 month-old rats, 4 weeks of continuous [mini-pump] IGF-1 infusion into the lateral ventricle reversed an age-related decreases in hippocampal glutamatergic N-methyl-D-aspartate ionotropic (NMDA) receptor subunits NR2A and $\mathrm{NR} 2 \mathrm{~B}\left(\mathrm{NMDAR}_{2 \mathrm{~A}}\right.$ and $\mathrm{NMDAR}_{2 \mathrm{~B}}$, respectively), subunits that are well-connected to learning and memory [200, 220]. Recent studies have also shown IGF-1 to protect cultured hippocampal cells (under stressful conditions) against NMDA-mediated excitotoxicity by modifying the phosphorylation of $\mathrm{NMDA}_{2 \mathrm{~B}}$ [221].

Rats undergoing 15 days of treadmill running show that regular training elevated the level of circulat- 
ing IGF-1 taken up into the hippocampus, where it is believed to modulate the effects of exercise [89]. Blocking hippocampal IGF-1 receptors during exercise significantly attenuated elevations in the transcription and translation of BDNF as well as that of its precursor, pro-BDNF. It also abrogated the signalling cascade downstream of BDNF/TrkB, including the phosphorylation of CaMKII and MAPK-II, paralleled by a dampened upregulation of proteins regulating synaptic function, such as synapsin I $[1,20]$. In addition, inhibiting the uptake of circulating IGF-1 with subcutaneous infusion of anti-serum blocked exercised-induced increases in the number of new granular cells in rats undergoing treadmill training [89]. Finally, while blocking IGF-1 did not affect exercise-enhanced learning acquisition, it attenuated the benefit to memory recall [1]. These studies suggest that while IGF-1 and BDNF co-operate to facilitate neurogenesis and synaptic plasticity, they may each play unique roles $[1,2,89$, 200].

\section{EXERCISE INCREASES NEUROTRANSMITTER LEVELS IN THE CENTRAL NERVOUS SYSTEM}

Alterations in neurotransmission as a result of age or pathology is a well-known contributor to impairments in learning and memory. Acute bouts of moderate to high intensity aerobic exercise (20 to 120 minutes) have been shown to influence a number of different neurotransmitter systems implicated in cognitive function and mood, including dopamine (DA), serotonin (5-HT), noradrenaline (NA), acetylcholine (ACh), glutamate, and gamma-aminobutyric acid (GABA) (Table 1; see reviews: [16, 222]). In this way, acute sessions of physical activity may enhance cognitive performance by increasing both blood flow and tissue content of neurotransmitters associated with cortical arousal, such as glutamate, NA and ACh [223-231]. Moreover, evidence suggests that increases in central neurotransmitters may co-operate with neurotrophins to promote beneficial long-term neuronal adaptations [222]. Indeed, a reciprocal relationship exists between several neurotransmitters and BDNF in the hippocampus [189, 203, 232-235]. These studies suggest that increases in neurotransmission and BDNF/TrkB signalling may converge to enhance neuronal survival, synaptic plasticity and neurogenesis, such as that observed to be coincident with increased physical activity $[4,5,236]$. The fol- lowing discussion of neurotransmitters is limited to those that have been most closely linked to BDNF in the pro-survival and signal transduction pathways; however, it should be noted that other transmitters, including ACh and GABA, have also been linked to the neuronal adaptations, cerebrovascular effects, and cognitive improvements associated with exercise [166, 227, 228, 237-241].

\section{Dopamine}

Positron emission tomography (PET) and postmortem biochemical analyses have revealed declines in DA synthesis, receptor binding, and receptor levels in the aging human brain [242-245]. These alterations may hold significance not only for mood and motor functions, well-known to be under dopaminergic governance, but from the perspective of neuroprotection in the aging brain.

Dopaminergic neurotransmission has been associated with enhanced BDNF signalling, a relationship well-described in vitro [246-248]. In embryonic neurons, $\mathrm{D}_{1}$ receptor agonism transactivates TrkB and several factors in its signalling pathway, accelerating morphological maturation, differentiation, and neurite outgrowth [248]. Similarly, pharmacological stimulation of the $\mathrm{D}_{1}-\mathrm{D}_{2}$ receptor hetero-oligomer was shown to increase BDNF production via a calcium signalling cascade in cultured striatal neurons and the adult rat brain [247]. In turn, BDNF originating from cortical neurons can elicit long-term adaptations by influencing the response of targets cells to DA, in part by controlling the expression of select DA receptor subtypes. This has been demonstrated in vivo using lesioning and gene-targeting experiments: mice lacking TrkB showed a global reduction in $\mathrm{D}_{1}$ mRNA [249], while BDNF-null mice and 6-hydroxydopamine (6-OHDA) lesioning of cortical dopaminergic neurons show BDNF to be necessary for normal expression of $\mathrm{D}_{3}$ receptor in the nucleus accumbens [250].

In both human and animals studies, moderate aerobic exercise such as treadmill running has been reported to increase DA synthesis, DA receptor expression and neurotransmission in a variety of structures, including the striatum, hippocampus, midbrain, pons-medulla and prefrontal cortex [210, 225-227, 251-259]. Some of these effects may be more profound in aged rodents, or under pathological conditions. For example, 8 weeks of was shown to upregulate the expression and activity of tyrosine hydroxylase, the rate-limiting enzyme in 
the synthesis of catecholamines, in aged mice but not in young mice, representing a reversal of its age-related decline [259]. In a neurotoxicity model of Parkinsonian dopaminergic cell loss, 28-days of intensive treadmill running enhanced DA bioavailability and neurotransmission both by increasing DA release and, by modulating the expression of its transporter, the time DA resides in the extracellular space [260]. These studies demonstrate that regular physical activity has the capacity to promote adaptive changes that facilitate dopaminergic transmission which might otherwise be compromise due to age or disease.

By enhancing both DA neurotransmission and BDNF production, exercise may promote neuroprotection of dopaminergic cells via a co-operative activation of pro-survival pathways. A 4-week history of treadmill running at speeds that incrementally built to the equivalent of a moderate intensity session (60 minutes/day, 5 days per week) was shown to completely protect against inflammation-induced dopaminergic neuronal loss in the substantia nigra and attenuated motor impairment in freely-behaving mice [246]. Neuroprotection in the nigrostriatal pathway was dependent on the activation of the BDNF-TrkB signalling pathway rather than modulation of microglial activation or cytokine/chemokine levels [246]. In contrast to the 4-week regimen, 2 weeks of exercise prior to the inflammatory challenge was insufficient to provide significant protection, which could be indicative of a minimal requirement for adequate exercise-facilitated BDNF translation to rescue neuronal loss in the striatum.

\section{Noradrenaline}

NA modulates a wide variety of brain functions, including attention, memory consolidation and memory retrieval [261-263]. Following both session of both moderate and intense exercise, tissue content of NA and its metabolites has been reported to be widely elevated throughout the brain (i.e. striatum, cortex, hippocampus, pons-medulla, and amygdala) as well as in the blood [226, 264-268]. Early microdialysis experiments showed that following 2 weeks of training on a treadmill ( 5 days per week, 1 hour at $25 \mathrm{~m} / \mathrm{min}, 3 \%$ slope; workload equivalent to $70 \%$ of $\mathrm{VO}_{2} \max$ ), rats that exercised for 1 to 2 hours showed increased levels of NA in both brain microdialysate and blood plasma (note: there was a 4 day rest after the initial, 2-week training for surgery and recovery) [266]. While both 1 and 2 hours were sufficient to significantly increase cortical NA levels within 40 minutes of the onset of treadmill running, the magnitude and duration of change was not equivalent: the maximal increase seen in a 1 hour session was fivefold over baseline, still evident 30 minutes after running cessation, while 2 hours of running increased NA levels 6.5 times over basal levels, with significant elevations lasting for 70 minutes [266].

Notably, exercise-induced upregulation of $B d n f$ is dependent on the activation of the transcription factor, cyclic AMP response element binding protein (CREB), which is in part facilitated by increased neurotransmission via the cAMP second messenger pathway [184, 269]. Selectively blocking $\beta$-adrenergic receptors throughout 3 days of voluntary wheel running abolishes $B d n f$ mRNA elevations within the hippocampus, suggesting noradrenergic signalling plays an important role in its upregulation [189]. Noradrenergic receptor antagonism was also found to blunt the exercise-mediated enhancement of learning and memory in rodents, as assessed by performance in contextual fear conditioning [270] and the Morris water maze [271]. In addition, activation of noradrenergic $\mathrm{G}$ protein-coupled receptors has been shown to transactivate BDNF/TrkB pathways, representing another means by which NA signalling participates in neuronal adaptations associated with exercise (Fig. 4A) [184, 189, 272-274].

Interestingly, noradrenergic signalling has also been shown to protect against $A \beta$ toxicity, achieved both through the transactivation of TrkB [275] and by facilitating increased expression of $B d n f$ [269]. It is possible that this represents an additional mechanism by which exercise-facilitated alterations in neurotransmission can confer neuroprotection. The NA system may also protect the brain by modulating the central inflammatory response, including that in response to $A \beta$, via adrenergic receptors on astrocytes and microglia [224, 276-278]. Selective lesioning of NA fibres has been shown to impair microglial migration and phagocytosis, reducing clearance of $A \beta$ in the hippocampus and frontal cortex [277]. This is a particularly interesting observation considering that degeneration of noradrenergic cells within the locus coeruleus has been associated not only with the severity of cognitive disturbance but with the cortical correlates of $A D$, including $A \beta$ plaque load and neurofibrillary tangles [277, 279, 280]. Noradrenergic lesioning also exacerbates lipopolysaccharide (LPS)-induced systemic inflammation, which is positively correlated to levels of hippocampal pro-inflammatory cytokines 

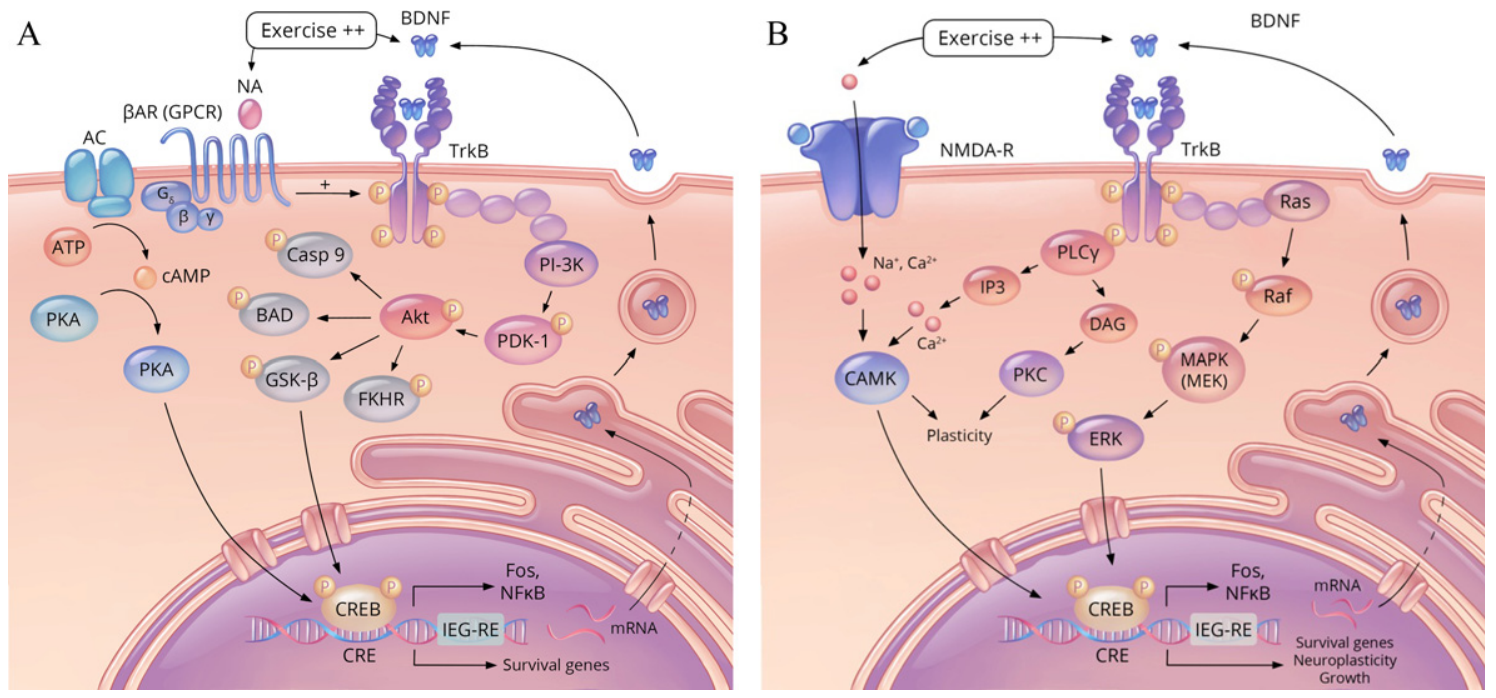

Fig. 4. Exercise-activated pathways regulating growth, survival, and neuroplasticity. (A) Schematic representation of the effect of increased noradrenaline (NA)-signalling and brain-derived neurotrophic factor (BDNF) / tropomyosin receptor kinase B (TrkB) signalling. Noradrenaline binds to the $\beta$-adrenergic receptor ( $\beta A R$ ), a G protein-coupled receptor (GPCR) which can initiate a cyclic adenosine monophosophate (cAMP) pathway to phosphorylate (and activate) the transcription factor cAMP response element-binding protein (CREB). In addition, NA-mediated signalling can augment BDNF signalling pathways by transactivating its receptor, TrkB. Phosphorylation of TrkB initiates the phosphatidylinositol-3 kinase (PI-3K) pathway to activate protein kinase B (Akt), which phosphorylates glycogen synthase kinase 3- $\beta$ (GSK- $\beta$ ), deactivating it, in turn increasing CREB activity. Phosphorylated CREB transcribes a number of pro-survival genes, such as Immediate-Early Gene-Regulatory Element (IEG-RE), and nuclear factor kappa-light-chain-enhancer of activated B cells (NFkB). In addition, it acts to further promote the transcription of BDNF and TrkB. Proteins that are deactivated by Akt include a number of pro-apoptotic factors (i.e. Casp 9, FKHR, and BAD) (shown in dark grey). Activated proteins and kinases are shown in pinks and blue, and activated CREB, in yellow. Additional abbreviations: adenosine triphosphate (ATP); Bcl-2-associated death promoter (BAD); cAMP response element (CRE); caspase 9 (Casp 9); forkhead transcription factor (FKHR); protein kinase A (PKA); phosphoinositide-dependent protein kinase-1 (PDK-1). (B) Two additional exercise-facilitated pathways involved in the growth, survival and plasticity pathways are the mitogen-activated protein kinases/extracellular signal-regulated kinases pathway (MAPS/ERK) and the phospholipase $\mathrm{C} \gamma / \mathrm{Ca} 2+/$ calmodulin-dependent protein kinase II (PLC $\gamma / \mathrm{CaMKII})$ pathway. Glutamate NMDA receptors activity also facilitates the effect of exercise on CREB activation. These pathways, like the PI-3K pathway, have also been shown to be involved BDNF/TrkB activation in promoting genes involved in survival and neuroplasticity. Activated proteins and kinases are shown in pinks and blue, and activated CREB, in yellow. Additional abbreviations: $\mathrm{Ca}^{2+}$ /calmodulin-dependent protein kinase (CAMK), diacyl-glycerol (DAG), Mitogen-activated protein kinase kinase (MEK), inositol trisphosphate (IP3), protein kinase C (PKC) [184, 287, 345, 346].

and microglial activation in aged rats [281]. Serum and BDNF levels were reduced in rats who were pre-treated with a selective noradrenergic toxin prior to receiving LPS [281]. Collectively, NA has been shown to play a number of important neuroprotective roles, both by transactivating TrkB and participating in the clearance of toxic peptides by microglia. It is possible that exercise may support these roles by facilitating NA neurotransmission.

\section{Serotonin}

Declines in the serotonergic system have been described in the aging human brain, and include decreased levels of 5- $\mathrm{HT}_{2}$ receptor in the prefrontal cortex as well as reduced binding capacity [245, 282]. In addition, post-mortem analyses of patients with mild cognitive impairment have revealed a global reduction in $5-\mathrm{HT}_{1 \mathrm{~A}}$ and $5-\mathrm{HT}_{2 \mathrm{~A}}$ receptors [283]. Activation of $5-\mathrm{HT}_{1 \mathrm{~A}}$ receptors has been shown to be associated with decreased NMDAR-mediated currents in pyramidal neurons of the prefrontal cortex, which in turn destabilises $\mathrm{NMDA}_{2 \mathrm{~B}}$ receptors; in contrast, activation of $5-\mathrm{HT}_{2 \mathrm{~A} / 2 \mathrm{C}}$ receptors increases NMDA receptor-mediated currents by activating intracellular signalling cascades [284-286]. These observations are of relevance when considering the role of NMDA-mediated signalling in LTP and synaptic plasticity. Indeed, exercise-enhanced learning has been associated with the downregulation of $5-\mathrm{HT}_{1 \mathrm{~A}}$ receptors and, conversely, upregulation of $5-\mathrm{HT}_{2 \mathrm{~A}}$ receptors in the hippocampus [287-289]. The inhibition of $5-\mathrm{HT}_{1 \mathrm{~A}}$ (a $\mathrm{G}_{\mathrm{i}}$ protein-coupled receptor) and activation of 5-HT $2 \mathrm{~A}$ (a $\mathrm{G}_{\mathrm{s}}$ protein-coupled recep- 
tor) results in elevated levels of cAMP, which in turn is involved in intracellular kinases and transcriptional factors supporting learning and memory [290]. Moreover, different 5-HT receptor subtypes have been demonstrated to play acute and opposing roles during various stages of neuronal development in vitro: where $5-\mathrm{HT}_{1 \mathrm{~A}}$ receptors promote self-renewal of precursor cells, $5-\mathrm{HT}_{2 \mathrm{~A} / \mathrm{C}}$ receptors effect both proliferation and promote neuronal differentiation [291].

Recent studies demonstrate 5-HT to be required for activity-induced neurogenesis in both young and aged mice [292, 293]. Mice deficient in tryptophan hydroxylase 2 (Tph2-/-), the enzyme mediating de novo 5-HT production in the raphe nucleus, exhibit selective depletion of brain-derived 5-HT. While Tph2-/- mice show normal baseline hippocampal neurogenesis, the proproliferative effect of voluntary running (6 days) was shown to required the release of central 5-HT [292]. Similarly, running-stimulated neurogenesis was reported to be impaired in mice deficient in Ang-converting enzyme 2 (ACE2), an enzyme which converts Ang II to Ang-(1-7); this modification transforms Ang signalling from a vasoconstrictive and pro-inflammatory signal to one that is vasodilatory and anti-inflammatory. ACE2 is also involved in the intestinal absorption of tryptophan, the precursor to serontonin, with ACE2-/- mice showing significant reductions in both blood and brain 5-HT levels [293]. Worth noting is that there is great variation in the literature pertaining to the tissue content of 5-HT following periods of physical activity, signifying that the duration and intensity of both acute sessions and chronic training impacts the synthesis of 5-HT, and the expression of its receptors and transporters, likely in a region-specific manner.

\section{Glutamate}

Glutamatergic neurotransmission, altered in normal aging and disease, is critically involved in facilitating neuronal plasticity and modulating both LTP and long-term depression (LTD) [294-297]. Aging has been associated with a decline of glutamate content in the prefrontal cortex and hippocampus, a reduction in high-affinity glutamate transporters and glutamatergic receptors, and reduced glutamate uptake capacity [298-300]. Expression of the NMDA receptor class is particularly influenced by advanced age $[200,298,301,302]$. As neuronal plasticity is in large part dependent on synaptic NMDAR activation, a decrease in synaptic NMDAR expression may functionally contribute to the age-related in memory and cognition [295, 303-305].

In rodents, short-term periods of voluntary running have been shown to modulate expression of glutamate receptors, upregulating NR2A and NR2B NMDA subunits within 3 and 7 days (respectively) [85, 236, 303] and glutamate receptor 5 (GlutR5), within 10 days [186]. Glutamatergic signalling has been shown to promote transcription of several genes involved in synaptic transmission as well as neuronal survival, via CREB activation. In this way, NMDA-mediated transmission has also been shown to contribute to the upregulation of BDNF and TrkB following exercise, further facilitating its effects [4]. Site-specific blockade of hippocampal NMDARs with MK-801 prevented increases in the transcription of $B d n f, \operatorname{Trk} B$, $C R E B$, and synapsin I mRNA observed in control animals following 3 days of wheel running (against $100 \mathrm{~g}$ resistance) $[4,5]$. In addition, rats given unrestricted access to a running wheel for 10 days had a significantly lower threshold for the induction of LTP in the dentate gyrus in vivo, as well as a potentiated LTP response to tetanic stimulation [186]. Similar results were demonstrated in vitro using hippocampal slices from running and non-running mice, showing that following 7-10 days, changes in NR2A and [to a lesser] extent NR2B were responsible for the augmentation of LTP and LTD [236]. More recent research shows that, together with GABA, exercisemediated increases in glutamatergic transmission also influences the integration of young adult-born neurons into neural networks, which may underlie improvements to specific cognitive tasks [296].

Notably, activation of extracellular NMDARs induces excitatory neurotoxicity that has been implicated in neurodegeneration, including that in AD. Studies have suggested that an inverse relationship exists between excessive glutamate levels in the brain and neurogenesis and/or cell survival, possibly due to extrasynaptic calcium influx. Activation of extracellular NMDARs has recently been linked to accelerated transcription of tau, concomitant with a suppression of the mitogen-activated protein kinases/extracellular signal-regulated kinases pathway (MAP/ERK) signalling pathway [306]. Rodent studies suggest that increased physical activity may ameliorate excessive glutamatergic activity, in part by regulating glutamate release and oxidation, as well as through the BDNF-mediated activation of the ERK pathway [163, 164, 307-309]. In the latter respect, it shares mechanistic similarities to treatment with low doses of antidepressants such as ketamine, 
an NMDAR antagonist that dampens spontaneous glutamate signalling [163]. Mice given free access to a running wheel for 6-8 weeks show a decrease hippocampal glutamate levels that correlated with increased hippocampal volume on magnetic resonance (MR) imaging [307]. These studies reveal that exercise-induced alterations to glutamatergic transmission play an important role in promoting the transcription of genes involved in synaptic plasticity, as well as in promoting cell survival.

\section{EXERCISE AND BDNF-MEDIATED PATHWAYS: NEUROPROTECTION AND SYNAPTIC PLASTICITY}

\section{Neurogenic and pro-survival pathways}

Exercise promotes neuronal differentiation, survival and plasticity through the phosphorylation of CREB by BDNF [310], with likely contributions by excitatory noradrenergic and glutamatergic signalling pathways. Foundational experiments demonstrated BDNF to be neuroprotective using hippocampal slices and cortical neurons in vitro: under apoptotic conditions, BDNF activates the phosphatidylinositol-3 kinase/protein kinase B pathway (PI-3k/AKT) as well as MAPS/ERK to stimulate the transcription of survival-promoting genes via CREB (Fig. 4A and B, respectively) [171, 287, 310-313]. The phospholipase $\mathrm{C} \gamma / \mathrm{Ca} 2+/$ calmodulindependent protein kinase II (PLC $\gamma / \mathrm{CaMKII})$ pathway is also activated by BDNF-TrkB signalling, again resulting in gene transcription of pro-survival genes [314]. In vivo studies have revealed notable mechanistic similarities between antidepressant treatments and exercise in rodents, with both activating excitatory pro-survival pathways. These studies offer insight into how exercise may mediate proliferative and/or neurogenic processes in the dentate gyrus via a combination of neuronal activation (i.e. synaptic transmission) and BDNF/TrkB signalling [184, 188, 189, 191, 315].

Recently, Ma et al. (2017) showed that BDNF/ TrkB signalling is responsible for the persistent adult neurogenesis in the dentate gyrus stimulated by chronic treatment with antidepressants, such as lowdose ketamine [163]. Ketamine treatment produced a rapid increase in BDNF levels in the dentate gyrus that coincided with accelerated differentiation of doublecortin positive $(\mathrm{DCX}+)$ progenitor cells into functionally mature neurons. Ablation of TrkB in progen- itor cells or disruption of TrkB-dependent ERK signalling blocked the generation of newborn neurons as well as the anti-depressant behavioural effects of the drug [163]. In addition, both antidepressants and voluntary exercise are known to activate the PI-3k/AKT pathway in the hippocampus, which promotes neuronal survival and inhibit apoptosis [287, 316, 317]. Chen et al. (2005) showed that 2 weeks of voluntary running in rats produced a robust increase in the phosphorylation of the full-length TrkB receptor, a result that was potentiated when animals were concurrently treated with an antidepressant [188-190, 287]. The study reported that levels of active (i.e. phosphorylated) forms of PI-3k, protein-dependent kinase-1 (PDK-1) and Akt were increased in the hippocampus, as were levels of phosphorylated glycogen synthase kinase-3 $\beta$ (GSK3 $\beta$, inactive form), which ultimately led to a significant enhancement of CREB [287]. Chen and colleagues further showed that phosphorylation of CREB was augmented when antidepressant treatment was combined with voluntary running (beyond either treatment alone) suggesting they work synergistically to modulate the PI-3k/AKT neuroprotective pathway, possibly a result of the transactivation of TrkB or a consequence of increased NA and/or 5-HT-mediated neuronal stimulation [287].

Another mechanism by which BDNF may faciliate neuroprotection is through the initiation of a synaptic NMDAR-associated intracellular cascade that attenuates the excitotoxicity that results from extrasynaptic NMDAR-mediated calcium influx [164, 303, 318]. Lau et al. (2015) found that BDNF/TrkB signalling induces protective adaptations, termed "adaptogenomics", by enhancing the nuclear calcium-inhibin $\beta$-A pathway [164]. In turn, inhibin $\beta$-A (or 'activin A', as a heterodimer) was shown to reduce extrasynaptic calcium influx and mitochondrial dysfunction, both of which contribute to excitotoxicity. Physical activity may therefore contribute to the neuroprotective adaptogenomic pathway by upregulating BDNF by enhancing synaptic NMDA activity while reducing extrasynaptic NMDA activity [164].

\section{Exercise, signal transduction and synaptic plasticity}

BDNF is known to alter gene transcription both pre- and post-synaptically [81, 160, 165, 319]. Quantitative analyses have revealed that elevated $\mathrm{BDNF} /$ TrkB signalling, resulting from short-term 
increases in physical activity, positively correlates with mRNA expression of several proteins involved in vesicular trafficking and neurotransmitter release. For instance, in freely running rats, syntaxin and synaptotagmin mRNA levels were shown to be upregulated by 3 days (continuing for at least 28 days), while synapsin $I$ was elevated at 3 and 7 days $[4,5,85$, 86]. Site-specific blockade of hippocampal TrkB was sufficient to abolish the exercise-induced increases in Bdnf, TrkB, CREB, synapsin I and synaptophysin reported after 3 days of voluntary running $[4,86]$. Blocking CaMKII had similar effects as TrkB inhibition, demonstrating its downstream involvement in upregulating both signalling molecules and $B d n f$ and $\operatorname{Trk} B$ expression in response to physical activity [4]. Together, these results demonstrate that shortterm exercise has the capacity to regulate synaptic transmission under the direction of BDNF $[4,5,86$, 320-322]. The effects of extended-periods of running are equally dependent on BDNF/TrkB signalling. After having undergone chronic treadmill running for a total of 4 weeks, mice showed increased hippocampal protein levels of BDNF, total and phosphorylated TrkB, and synaptotagmin. These molecular changes were associated with behavioural outcomes, as exercised mice showed improved performance on the passive avoidance test as compared to sedentary controls [81]. Again, TrkB inhibition abolished the exercise-induced increases in BDNF and synaptotagmin levels, and impaired performance on the same test of aversion memory [81].

In vitro studies suggest that alterations in protein synthesis in response to BDNF can occur on the order of hours and are regionally localised to dendrites and axons, with protein synthesis machinery residing in pre- and post-synaptic terminals [158, $171,319,323]$. The rapidly increased production of signal transduction molecules may be in part responsible for the relatively quick effects of exercise on mood and cognitive performance. By modulating the transcription of synaptic proteins such as synapsin I, synaptophysin, and synaptotagmin, exercise puts in place pre-synaptic structures to support enhanced neurotransmission. A complimentary increase in the expression of neurotransmitter receptor proteins, such as subunit-specific increases in NMDARs, further facilitates the enhancement of neurotransmission. As selective blockade of NMDARs and BDNF both abolished exercise-facilitated gene transcription, both neuronal activity and BDNF/TrkB signalling seem to be an essential part of both the pro-survival and plastic response.
BDNF has been shown to be involved in several forms of LTP. Using site-specific gene deletion, Zakharenko and colleagues dissociated the effects of BDNF released from pre-synaptic neurons in the $\mathrm{C} 1$ and $\mathrm{C} 3$ regions from that released post-synaptically at $\mathrm{C} 1$, finding that presynaptic release of BDNF from $\mathrm{C} 3$ was required to modulate a pre-synaptic component of LTP [319]. In particular, BDNF was shown to be required for a pre-synaptic component of theta burst LTP, which is thought to be of relevance for behavioural activity, as well as for the full expression of $200 \mathrm{~Hz}$ LTP. Exercise may then influence LTP by way of BDNF but also through its governance of neurotransmitter release, such as $\mathrm{ACh}$, which is found to be elevated in the hippocampus and cortex with increased physical activity [226, 227, 237]. An increased concentration of $\mathrm{ACh}$ in the hippocampus supports the generation of theta oscillations, which in turn, serves to facilitate synaptic plasticity, learning and memory [240, 324, 325]. Acute physical activity has also been reported to produce immediate and robust neuronal activation of the hippocampal formation, as measured by c-fos positive cells [315]. On-going movements (i.e. wheel running, walking, swimming, etc.) generate theta oscillations that are positively correlated to the force or intensity of these movements and remain elevated the duration of activity. These theta oscillations have been associated with glutamatergic inputs originating from the medial septal nucleus and/or the entorhinal cortex, as lesioning experiments have eliminated movement-related theta [315]. Recalling that physical activity is known to modulate the expression of NMDAR, it is interesting to note that changes in the levels of BDNF, $\mathrm{ACh}$, and NMDA-mediated signalling likely work synergistically to mediated enhancement of synaptic plasticity.

\section{CLOSING REMARKS}

In this review, we highlighted the many contributions of an active lifestyle to continued brain health. First, as discussed, the BDNF/TrkB pathways initiated by physical activity are involved in neuroprotection, synaptic plasticity, and neurogenesis. Knockout mice have demonstrated that BDNF is required for the enhancement of hippocampal neurogenesis following housing in enriched environments [326]. Moreover, intracerebroventricular injections of BDNF have mimicked the effects of 1 week of treadmill running on spatial and non-spatial learning 
[187], and chronic intrahippocampal administration of BDNF has been shown to rescue cognitive deficits following a ventricular injection of $A \beta$ in rats [327]. Of note, only enriched environments that include a running wheel were shown to increase BDNF levels, showing it may have a unique role in neuroprotection $[74,75,328]$. Indeed, much past literature has focused on the link between physical activity and neurogenesis, showing that physical activity alone is sufficient for increasing cell proliferation and promoting cell survival $[54,56,57]$. However some studies suggest that cognitive stimulation is an essential part of differentiating proliferating cells into neurons and integrating them into networks [41, 329]. Considerable efforts are now being made to better understand the complexities of adult neural stem cells and the dynamic range of states in which they can exist (for excellent review, see [63]). Moreover, though a greater proportion of adult neural stem cells have entered quiescence, current research centres on how certain stimuli may transition these cells from quiescence to a proliferative state. Nonetheless, mitigating the age-related decline in neurogenesis is only one way by which an active lifestyle can keep the brain 'young' [330]. Several decades of literature demonstrate its benefit to the neurons, glia and cerebrovaculature of the brain. In animal models of aging, disease and toxicity, physical exercise has been shown to upregulate TJs of the BBB and to protect the neurovascular unit. Exercise has also been shown to reduce markers of microglia activation in the brain of aged mice, further mitigating damage to the neurovascular unit [90, 95, 331-333]. Finally, exercise may also aid in the protection of an aging brain by increasing glymphatic clearance, and promoting the clearance and degradation of $\mathrm{A} \beta[76$, 94, 96-99].

Both animal and human literature suggest that many of the protective benefits of exercise are orchestrated by elevations in central and peripheral neurotrophic factors. Increases in neurotrophic levels have been reported to be associated with both acute sessions of high-intensity exercise and chronic aerobic exercise. In healthy, young human adults, BDNF levels in the serum were shown to increase during acute sessions of high-intensity anaerobic cycling (correlating with lactate levels), but not at workloads below the ventilatory threshold [7]. However, BDNF in plasma were shown to be elevate during moderate-intensity endurance exercise, such as a 4hour row at a workload 10-15\% below the lactate threshold [9]. Other studies still show that both acute high-intensity exercise and regular, moderate aerobic exercise increases serum levels of BDNF and IGF-1, and improves some measures of memory and cognition in young participants $[8,13,334,335]$. Notably, a recent meta-analysis of 29 studies showed that aerobic exercise, but not resistance training, increased resting concentrations of peripheral BDNF [183]. As circulating BDNF receives contributions from both the brain and other sources, including contracting muscle, this discrepancy may reflect a difference in the relative contribution of these sources during aerobic and anaerobic exercise.

Many studies demonstrate a correlation between BDNF and/or work levels and improved performance in various tests of memory and cognition (with the support of many meta-analyses). Still, the degree to which exercise specifically affects memory and cognition in young participants, independent of mood or acute effects on attention, lacks firm consensus [16, 183, 335-338]. To-date, clinic research has been somewhat limited by study size and is not often sex-balance; it also shows great variability in experimental and sampling protocols. It is possible that performance on certain memory testing may be more malleable to acute exercise sessions than others and augmented via different mechanisms, such as rapid changes in blood flow or the release of neurotransmitters that modulate attention. In this way, it is possible that acute cognitive changes may be independent of elevated BDNF and more reliant on other rapid physiological processes. In contrast, improvements to memory, cognition or executive function that correlate with regular exercise may be a result of long-term neuronal adaptations. Cognitive improvements associated with exercise are most striking in aged participants, and possibly even more so in the eldest of participants due to an age-dependent decline in baseline BDNF levels relative to young individuals $[18,23]$. In cognitively-unimpaired aging participants as well as those with mild cognitive impairment, aerobic activity correlates with a reduced risk of developing deficits in executive functions and a reduced incidence of dementia [18, 21, 22]. In these prospective studies, the intensity, duration and frequency of exercise correlate with improved scores on tests of memory and cognition, though it is worth noting that sex differences may emerge. Moreover, while these parameters correlate to performance, it is important to recognise the feasibility of intense exercise, even with supervision, in some elderly populations, particularly following an event such as a stroke. To this end, 
even light and moderate exercise, with regularity, has been shown to be beneficial.

Together, human and preclinical studies shape a powerful story demonstrating that physical activity can counteract many aspects of decline in the brain's environment associated with aging. Because 'exercise regimens' of various work-levels and durations seem to produce similar effects in animals and humans, we are able to gain valuable insight into the downstream mechanisms by which physical activity might contribute to continued brain health. It is important to recognise that the topic addressed in this review cover only a fraction of the potential benefits of exercise - particularly regular, aerobic exercise - to adaptive changes in the hippocampus. The objective of this review was to highlight the protective effects of neurotropic factors to the brain and how, in addition to the well-established enhancement of synaptic plasticity, adaptive effects may include changes in support for the BBB, clearance of toxic species and reduced neuroinflammation. These rest heavily on brain-derived alterations driving gene transcription. The relative contributions that centrally vs peripherally-derived trophic factors have to a single cognitive test score is likely dependent on whether testing follows an acute, isolated session or a history of regular exercise. Still, recent literature provides evidence to support a strong (and, perhaps underappreciated) contribution from peripheral neurotrophins and hormones to hippocampus adaptations, such as those that are muscle- or liverderived [1, 2, 89, 192, 339-344]. In addition, it is possible that acute changes in cortical activity during exercise may contribute to long-term adaptations (for an excellent recent review, see [315]). Therefore, the lasting impression should be one that emphasizes that different durations, intensities, and forms of exercise may contribute unique benefits to the brain, though long-term exercise provides the greatest and longest-lasting benefits. Individual persons may have individual limitations to the types of exercise they do, possibly restricted by age or mobility. It is also possible that sex and polymorphics differences may influence the degree to which exercise influences the different systems discussed here. Indeed, a limitation of animal and human research alike is the lack of well-powered, sex-balanced studies. Nonetheless, there is a great body of evidence that demonstrates that an active lifestyle bestows a diverse set of benefits that mitigate the age-related changes in the brain that contribute to cognitive decline.

\section{CONFLICT OF INTEREST}

The authors have no conflict of interest to report.

\section{ACKNOWLEDGMENTS}

We thank our medical illustrator, Hang Yu Lin, for her wonderful contributions to this paper.

\section{REFERENCES}

[1] Ding Q, Vaynman S, Akhavan M, Ying Z, GomezPinilla F. Insulin-like growth factor I interfaces with brain-derived neurotrophic factor-mediated synaptic plasticity to modulate aspects of exercise-induced cognitive function. Neuroscience. 2006;140:823-33. doi: 10.1016/j.neuroscience.2006.02.084

[2] Ding Q, Vaynman S, Souda P, Whitelegge JP, GomezPinilla F. Exercise affects energy metabolism and neural plasticity-related proteins in the hippocampus as revealed by proteomic analysis. Eur J Neurosci. 2006;24:1265-76. doi: 10.1111/j.1460-9568.2006.05026.x

[3] Neeper SA, Gomez-Pinilla F, Choi J, Cotman C. Exercise and brain neurotrophins. Nature. 1995;373:109. doi: $10.1038 / 373109 \mathrm{a} 0$

[4] Vaynman S, Ying Z, Gomez-Pinilla F. Interplay between brain-derived neurotrophic factor and signal transduction modulators in the regulation of the effects of exercise on synaptic-plasticity. Neuroscience. 2003;122:647-57. doi: 10.1016/j.neuroscience.2003.08.001

[5] Vaynman S, Ying Z, Gomez-Pinilla F. Hippocampal BDNF mediates the efficacy of exercise on synaptic plasticity and cognition. Eur J Neurosci. 2004;20:2580-90. doi: 10.1111/j.1460-9568.2004.03720.x

[6] Speisman RB, Kumar A, Rani A, Foster TC, Ormerod BK. Daily exercise improves memory, stimulates hippocampal neurogenesis and modulates immune and neuroimmune cytokines in aging rats. Brain Behav Immun. 2013;28:2543. doi: 10.1016/j.bbi.2012.09.013

[7] Ferris LT, Williams JS, Shen CL. The effect of acute exercise on serum brain-derived neurotrophic factor levels and cognitive function. Med Sci Sports Exerc. 2007;39:72834. doi: 10.1249/mss.0b013e31802f04c7

[8] Griffin EW, Mullally S, Foley C, Warmington SA, O'Mara SM, Kelly AM. Aerobic exercise improves hippocampal function and increases BDNF in the serum of young adult males. Physiol Behav. 2011;104:934-41. doi: 10.1016/j.physbeh.2011.06.005

[9] Rasmussen P, Brassard P, Adser H, Pedersen MV, Leick L, Hart E, et al. Evidence for a release of brainderived neurotrophic factor from the brain during exercise. Exp Physiol. 2009;94:1062-9. doi: 10.1113/expphysiol.2009.048512

[10] Tang SW, Chu E, Hui T, Helmeste D, Law C. Influence of exercise on serum brain-derived neurotrophic factor concentrations in healthy human subjects. Neurosci Lett. 2008;431:62-5. doi: 10.1016/j.neulet.2007.11.019

[11] Bherer L, Erickson KI, Liu-Ambrose T. A review of the effects of physical activity and exercise on cognitive and brain functions in older adults. J Aging Res. 2013;2013:657508. doi: 10.1155/2013/657508 
[12] Gomez-Pinilla F, Hillman C. The influence of exercise on cognitive abilities. Compr Physiol. 2013;3:403-28. doi: 10.1002/cphy.c110063

[13] Jeon YK, Ha CH. Expression of brain-derived neurotrophic factor, IGF-1 and cortisol elicited by regular aerobic exercise in adolescents. J Phys Ther Sci. 2015;27:737-41. doi: 10.1589/jpts.27.737

[14] Lange-Asschenfeldt C, Kojda G. Alzheimer's disease, cerebrovascular dysfunction and the benefits of exercise: from vessels to neurons. Exp Gerontol. 2008;43:499-504. doi: 10.1016/j.exger.2008.04.002

[15] Salmon P. Effects of physical exercise on anxiety, depression, and sensitivity to stress: A unifying theory. Clin Psychol Rev. 2001;21:33-61. doi: 10.1016/S02727358(99)00032-X

[16] Basso JCS, W.A. The effects of acute exercise on mood, congition, neurophysiology and neurochemical pathways: A review. Brain Plasticity. 2017;2:127-52. doi: 10.3233/BPL-160040

[17] Colcombe S, Kramer AF. Fitness effects on the cognitive function of older adults: a meta-analytic study. Psychol Sci. 2003;14:125-30. doi: 10.1111/14679280.t01-1-01430

[18] Larson EB, Wang L, Bowen JD, McCormick WC, Teri $\mathrm{L}$, Crane P, et al. Exercise is associated with reduced risk for incident dementia among persons 65 years of age and older. Ann Intern Med. 2006;144:73-81. doi: 10.7326/0003-4819-144-2-200601170-00004

[19] Cotman CW, Berchtold NC. Exercise: a behavioral intervention to enhance brain health and plasticity. Trends Neurosci. 2002;25:295-301. doi: 10.1016/S01662236(02)02143-4

[20] Cotman CW, Berchtold NC, Christie LA. Exercise builds brain health: Key roles of growth factor cascades and inflammation. Trends Neurosci. 2007;30:464-72. doi: 10.1016/j.tins.2007.06.011

[21] Clark S, Parisi J, Kuo J, Carlson MC. Physical activity is associated with reduced risk of executive function impairment in older women. J Aging Health. 2016;28:726-39. doi: $10.1177 / 0898264315609908$

[22] Heyn P, Abreu BC, Ottenbacher KJ. The effects of exercise training on elderly persons with cognitive impairment and dementia: a meta-analysis. Arch Phys Med Rehabil. 2004;85:1694-704. doi: 10.1016/j.apmr.2004.03.019

[23] Leckie RL, Oberlin LE, Voss MW, Prakash RS, SzaboReed A, Chaddock-Heyman L, et al. BDNF mediates improvements in executive function following a 1-year exercise intervention. Front Hum Neurosci. 2014;8:985. doi: 10.3389/fnhum.2014.00985

[24] de Assis GG, de Almondes KM. Exercise-dependent BDNF as a modulatory factor for the executive processing of individuals in course of cognitive decline. A systematic review. Front Psychol. 2017;8:584. doi: 10.3389/fpsyg.2017.00584

[25] Carlsson A. Brain neurotransmitters in aging and dementia: similar changes across diagnostic dementia groups. Gerontology. 1987;33:159-67. doi: 10.1159/000212870

[26] Peters R. Ageing and the brain. Postgrad Med J. 2006;82:84-8. doi: 10.1136/pgmj.2005.036665

[27] Schliebs R, Arendt T. The cholinergic system in aging and neuronal degeneration. Behavioural Brain Research. 2011;221:555-63. doi: 10.1016/j.bbr.2010.11.058

[28] Sonntag WE, Eckman DM, Ingraham J, Riddle DR. Regulation of Cerebrovascular Aging. In: Riddle DR, editor. Brain Aging: Models, Methods, and Mechanisms. Boca Raton (FL)2007.
[29] Sonntag WE, Ramsey M, Carter CS. Growth hormone and insulin-like growth factor-1 (IGF-1) and their influence on cognitive aging. Ageing Res Rev. 2005;4:195-212. doi: 10.1016/j.arr.2005.02.001

[30] Mattson MP, Magnus T. Ageing and neuronal vulnerability. Nat Rev Neurosci. 2006;7:278-94. doi: 10.1038/nrn1886

[31] Attems J, Jellinger KA. The overlap between vascular disease and Alzheimer's disease-lessons from pathology. BMC Med. 2014;12:206. doi: 10.1186/s12916-0140206-2

[32] Laske C, Stransky E, Leyhe T, Eschweiler GW, Maetzler W, Wittorf A, et al. BDNF serum and CSF concentrations in Alzheimer's disease, normal pressure hydrocephalus and healthy controls. J Psychiatr Res. 2007;41:387-94. doi: 10.1016/j.jpsychires.2006.01.014

[33] Ota M, Yasuno F, Ito H, Seki C, Nozaki S, Asada T, et al. Age-related decline of dopamine synthesis in the living human brain measured by positron emission tomography with 1-[ $\beta-11 C] D O P A$. Life Sci. 2006;79:730-6. doi: 10.1016/j.lfs.2006.02.017

[34] He J, Farias S, Martinez O, Reed B, Mungas D, Decarli C. Differences in brain volume, hippocampal volume, cerebrovascular risk factors, and apolipoprotein E4 among mild cognitive impairment subtypes. Arch Neurol. 2009;66:1393-9. doi: 10.1001/archneurol.2009.252

[35] Michalski B, Corrada MM, Kawas CH, Fahnestock M. Brain-derived neurotrophic factor and TrkB expression in the "oldest-old," the 90+ Study: correlation with cognitive status and levels of soluble amyloid-beta. Neurobiol Aging. 2015;36:3130-9. doi: 10.1016/j.neurobiolaging.2015.08.022

[36] Driscoll I, Hamilton DA, Petropoulos H, Yeo RA, Brooks WM, Baumgartner RN, et al. The aging hippocampus: cognitive, biochemical and structural findings. Cereb Cortex. 2003;13:1344-51. doi: 10.1093/cercor/bhg081

[37] Erickson KI, Prakash RS, Voss MW, Chaddock L, Heo S, McLaren M, et al. Brain-derived neurotrophic factor is associated with age-related decline in hippocampal volume. J Neurosci. 2010;30:5368-75. doi: 10.1523/JNEUROSCI.6251-09.2010

[38] von Bohlen und Halbach O. Involvement of BDNF in agedependent alterations in the hippocampus. Front Aging Neurosci. 2010;2. doi: 10.3389/fnagi.2010.00036

[39] Mathews KJ, Allen KM, Boerrigter D, Ball H, Shannon Weickert C, Double KL. Evidence for reduced neurogenesis in the aging human hippocampus despite stable stem cell markers. Aging Cell. 2017;16:1195-9. doi: 10.1111/acel.12641

[40] Hattiangady B, Rao MS, Shetty GA, Shetty AK. Brainderived neurotrophic factor, phosphorylated cyclic AMP response element binding protein and neuropeptide $\mathrm{Y}$ decline as early as middle age in the dentate gyrus and CA1 and CA 3 subfields of the hippocampus. Exp Neurol. 2005;195:353-71. doi: 10.1016/j.expneurol.2005. 05.014

[41] Kronenberg G, Bick-Sander A, Bunk E, Wolf C, Ehninger D, Kempermann G. Physical exercise prevents agerelated decline in precursor cell activity in the mouse dentate gyrus. Neurobiol Aging. 2006;27:1505-13. doi: 10.1016/j.neurobiolaging.2005.09.016

[42] Silhol M, Bonnichon V, Rage F, Tapia-Arancibia L. Agerelated changes in brain-derived neurotrophic factor and tyrosine kinase receptor isoforms in the hippocampus and hypothalamus in male rats. Neuroscience. 2005; 132:61324. doi: 10.1016/j.neuroscience.2005.01.008 
[43] Sonntag WE, Lynch CD, Cooney PT, Hutchins PM. Decreases in cerebral microvasculature with age are associated with the decline in growth hormone and insulin-like growth factor 1. Endocrinology. 1997;138:3515-20. doi: 10.1210/endo.138.8.5330

[44] O'Shea A, Cohen RA, Porges EC, Nissim NR, Woods AJ. Cognitive aging and the hippocampus in older adults. Front Aging Neurosci. 2016;8:298. doi: 10.3389/fnagi.2016.00298

[45] von Bohlen und Halbach O, Krause S, Medina D, Sciarretta C, Minichiello L, Unsicker K. Regional- and age-dependent reduction in trkB receptor expression in the hippocampus is associated with altered spine morphologies. Biol Psychiatry. 2006;59:793-800. doi: 10.1016/j.biopsych.2005.08.025

[46] Ben Abdallah NM, Slomianka L, Vyssotski AL, Lipp HP. Early age-related changes in adult hippocampal neurogenesis in C57 mice. Neurobiol Aging. 2010;31:151-61. doi: 10.1016/j.neurobiolaging.2008.03.002

[47] Daynac M, Morizur L, Chicheportiche A, Mouthon MA, Boussin FD. Age-related neurogenesis decline in the subventricular zone is associated with specific cell cycle regulation changes in activated neural stem cells. Sci Rep. 2016;6:21505. doi: 10.1038/srep21505

[48] Rex CS, Lauterborn JC, Lin CY, Kramar EA, Rogers GA, Gall CM, et al. Restoration of long-term potentiation in middle-aged hippocampus after induction of brain-derived neurotrophic factor. J Neurophysiol. 2006;96:677-85. doi: 10.1152/jn.00336.2006

[49] Korte M, Carroll P, Wolf E, Brem G, Thoenen H, Bonhoeffer T. Hippocampal long-term potentiation is impaired in mice lacking brain-derived neurotrophic factor. Proc Natl Acad Sci U S A. 1995;92:8856-60.

[50] Kuhn HG, Dickinson-Anson H, Gage FH. Neurogenesis in the dentate gyrus of the adult rat: age-related decrease of neuronal progenitor proliferation. J Neurosci. 1996;16:2027-33.

[51] Greene E, Naranjo JN. Degeneration of hippocampal fibers and spatial memory deficit in the aged rat. Neurobiol Aging. 1987;8:35-43.

[52] Granger R, Deadwyler S, Davis M, Moskovitz B, Kessler M, Rogers G, et al. Facilitation of glutamate receptors reverses an age-associated memory impairment in rats. Synapse. 1996;22:332-7. doi: 10.1002/(SICI)10982396(199604)22:4<332::AID-SYN4>3.0.CO;2-C

[53] Lynch G, Rex CS, Gall CM. Synaptic plasticity in early aging. Ageing Res Rev. 2006;5:255-80. doi: 10.1016/j.arr.2006.03.008

[54] Marlatt MW, Potter MC, Lucassen PJ, van Praag H. Running throughout middle-age improves memory function, hippocampal neurogenesis, and BDNF levels in female C57BL/6J mice. Dev Neurobiol. 2012;72:943-52. doi: 10.1002/dneu.22009

[55] Park H, Poo MM. Neurotrophin regulation of neural circuit development and function. Nat Rev Neurosci. 2013;14:723. doi: $10.1038 / \mathrm{nrn} 3379$

[56] van Praag H, Christie BR, Sejnowski TJ, Gage FH. Running enhances neurogenesis, learning, and longterm potentiation in mice. Proc Natl Acad Sci U S A. 1999;96:13427-31. doi: 10.1073/pnas.96.23.13427

[57] van Praag H, Shubert T, Zhao C, Gage FH. Exercise enhances learning and hippocampal neurogenesis in aged mice. J Neurosci. 2005;25:8680-5. doi: 10.1523/ JNEUROSCI.1731-05.2005

[58] Leal G, Comprido D, Duarte CB. BDNF-induced local protein synthesis and synaptic plasticity. Neuropharma- cology. 2014;76 Pt C:639-56. doi: 10.1016/j.neuropharm. 2013.04.005

[59] Leal G, Comprido D, de Luca P, Morais E, Rodrigues L, Mele M, et al. The RNA-binding protein hnRNP K mediates the effect of BDNF on dendritic mRNA metabolism and regulates synaptic NMDA receptors in hippocampal neurons. eNeuro. 2017;4. doi: 10.1523/ENEURO.026817.2017

[60] Bond AM, Ming GL, Song H. Adult mammalian neural stem cells and neurogenesis: five decades later. Cell Stem Cell. 2015;17:385-95. doi: 10.1016/j.stem.2015.09.003

[61] Boldrini M, Fulmore CA, Tartt AN, Simeon LR, Pavlova I, Poposka V, et al. Human hippocampal neurogenesis persists throughout aging. Cell Stem Cell. 2018;22:589-99 e5. doi: 10.1016/j.stem.2018.03.015

[62] Eriksson PS, Perfilieva E, Bjork-Eriksson T, Alborn AM, Nordborg C, Peterson DA, et al. Neurogenesis in the adult human hippocampus. Nat Med. 1998;4:1313-7. doi: $10.1038 / 3305$

[63] Katsimpardi L, Lledo PM. Regulation of neurogenesis in the adult and aging brain. Curr Opin Neurobiol. 2018;53:131-8. doi: 10.1016/j.conb.2018.07.006

[64] Sorrells SF, Paredes MF, Cebrian-Silla A, Sandoval K, Qi D, Kelley KW, et al. Human hippocampal neurogenesis drops sharply in children to undetectable levels in adults. Nature. 2018;555:377-81. doi: 10.1038/nature25975

[65] Spalding KL, Bergmann O, Alkass K, Bernard S, Salehpour M, Huttner HB, et al. Dynamics of hippocampal neurogenesis in adult humans. Cell. 2013;153:1219-27. doi: 10.1016/j.cell.2013.05.002

[66] Encinas JM, Fitzsimons CP. Gene regulation in adult neural stem cells. Current challenges and possible applications. Adv Drug Deliv Rev. 2017;120:118-32. doi: 10.1016/j.addr.2017.07.016

[67] Lugert S, Basak O, Knuckles P, Haussler U, Fabel $\mathrm{K}$, Gotz M, et al. Quiescent and active hippocampal neural stem cells with distinct morphologies respond selectively to physiological and pathological stimuli and aging. Cell Stem Cell. 2010;6:445-56. doi: 10.1016/j.stem.2010.03.017

[68] Noguchi H, Kimura A, Murao N, Matsuda T, Namihira M, Nakashima K. Expression of DNMT1 in neural stem/precursor cells is critical for survival of newly generated neurons in the adult hippocampus. Neurosci Res. 2015;95:1-11. doi: 10.1016/j.neures.2015.01.014

[69] Katsimpardi L, Litterman NK, Schein PA, Miller CM, Loffredo FS, Wojtkiewicz GR, et al. Vascular and neurogenic rejuvenation of the aging mouse brain by young systemic factors. Science. 2014;344:630-4. doi: $10.1126 /$ science. 1251141

[70] Katsimpardi L, Rubin LL. Young systemic factors as a medicine for age-related neurodegenerative diseases. Neurogenesis (Austin). 2015;2:e1004971. doi: 10.1080/23262133.2015.1004971

[71] Villeda SA, Plambeck KE, Middeldorp J, Castellano JM, Mosher KI, Luo J, et al. Young blood reverses age-related impairments in cognitive function and synaptic plasticity in mice. Nat Med. 2014;20:659-63. doi: 10.1038/nm.3569

[72] Kempermann G, Brandon EP, Gage FH. Environmental stimulation of $129 / \mathrm{SvJ}$ mice causes increased cell proliferation and neurogenesis in the adult dentate gyrus. Curr Biol. 1998;8:939-42. doi: 10.1016/S09609822(07)00377-6

[73] Kempermann G, Kuhn HG, Gage FH. More hippocampal neurons in adult mice living in an enriched environment. Nature. 1997;386:493-5. doi: 10.1038/386493a0 
[74] Kobilo T, Liu QR, Gandhi K, Mughal M, Shaham $\mathrm{Y}$, van Praag H. Running is the neurogenic and neurotrophic stimulus in environmental enrichment. Learn Mem. 2011;18:605-9. doi: 10.1101/1m.2283011

[75] Vivar C, Potter MC, van Praag H. All about running: synaptic plasticity, growth factors and adult hippocampal neurogenesis. Curr Top Behav Neurosci. 2013;15:189210. doi: 10.1007/7854_2012_220

[76] Maliszewska-Cyna E, Xhima K, Aubert I. A comparative study evaluating the impact of physical exercise on disease progression in a mouse model of Alzheimer's disease. J Alzheimers Dis. 2016;53:243-57. doi: 10.3233/JAD150660

[77] Baruch DE, Swain RA, Helmstetter FJ. Effects of exercise on Pavlovian fear conditioning. Behav Neurosci. 2004;118:1123-7. doi: 10.1037/0735-7044.118.5.1123

[78] Falls WA, Fox JH, MacAulay CM. Voluntary exercise improves both learning and consolidation of cued conditioned fear in C57 mice. Behav Brain Res. 2010;207:321-31. doi: 10.1016/j.bbr.2009.10.016

[79] O'Callaghan RM, Ohle R, Kelly AM. The effects of forced exercise on hippocampal plasticity in the rat: A comparison of LTP, spatial- and non-spatial learning. Behav Brain Res. 2007;176:362-6. doi: 10.1016/j.bbr.2006.10.018

[80] Chen HI, Lin LC, Yu L, Liu YF, Kuo YM, Huang AM, et al. Treadmill exercise enhances passive avoidance learning in rats: the role of down-regulated serotonin system in the limbic system. Neurobiol Learn Mem. 2008;89:489-96. doi: 10.1016/j.nlm.2007.08.004

[81] Liu YF, Chen HI, Yu L, Kuo YM, Wu FS, Chuang JI, et al. Upregulation of hippocampal TrkB and synaptotagmin is involved in treadmill exercise-enhanced aversive memory in mice. Neurobiol Learn Mem. 2008;90:81-9. doi: 10.1016/j.nlm.2008.02.005

[82] Aguiar AS, Jr., Castro AA, Moreira EL, Glaser V, Santos AR, Tasca CI, et al. Short bouts of mild-intensity physical exercise improve spatial learning and memory in aging rats: involvement of hippocampal plasticity via AKT, CREB and BDNF signaling. Mech Ageing Dev. 2011;132:560-7. doi: 10.1016/j.mad.2011.09.005

[83] Albeck DS, Sano K, Prewitt GE, Dalton L. Mild forced treadmill exercise enhances spatial learning in the aged rat. Behav Brain Res. 2006;168:345-8. doi: 10.1016/j.bbr.2005.11.008

[84] Gomez-Pinilla F, Vaynman S, Ying Z. Brain-derived neurotrophic factor functions as a metabotrophin to mediate the effects of exercise on cognition. Eur J Neurosci. 2008;28:2278-87. doi: 10.1111/j.14609568.2008.06524.x

[85] Molteni R, Ying Z, Gomez-Pinilla F. Differential effects of acute and chronic exercise on plasticity-related genes in the rat hippocampus revealed by microarray. Eur J Neurosci. 2002;16:1107-16. doi: 10.1046/j.14609568.2002.02158.x

[86] Vaynman SS, Ying Z, Yin D, Gomez-Pinilla F. Exercise differentially regulates synaptic proteins associated to the function of BDNF. Brain Res. 2006;1070:124-30. doi: 10.1016/j.brainres.2005.11.062

[87] van Praag H, Fleshner M, Schwartz MW, Mattson MP. Exercise, energy intake, glucose homeostasis, and the brain. J Neurosci. 2014;34:15139-49. doi: 10.1523/JNEUROSCI.2814-14.2014

[88] Markowska AL, Mooney M, Sonntag WE. Insulinlike growth factor-1 ameliorates age-related behavioral deficits. Neuroscience. 1998;87:559-69. doi: 10.1016/S0 306-4522(98)00143-2
[89] Trejo JL, Carro E, Torres-Aleman I. Circulating insulinlike growth factor I mediates exercise-induced increases in the number of new neurons in the adult hippocampus. J Neurosci. 2001;21:1628-34. doi: 10.1523/ JNEUROSCI.21-05-01628.2001

[90] Gomes da Silva S, Simoes PS, Mortara RA, Scorza FA, Cavalheiro EA, da Graca Naffah-Mazzacoratti M, et al. Exercise-induced hippocampal anti-inflammatory response in aged rats. J Neuroinflammation. 2013;10:61. doi: 10.1186/1742-2094-10-61

[91] Park M, Levine H, Toborek M. Exercise protects against methamphetamine-induced aberrant neurogenesis. Sci Rep. 2016;6:34111. doi: 10.1038/srep34111

[92] Soto I, Graham LC, Richter HJ, Simeone SN, Radell JE, Grabowska W, et al. APOE stabilization by exercise prevents aging neurovascular dysfunction and complement induction. PLoS Biol. 2015;13:e1002279. doi: 10.1371/journal.pbio.1002279

[93] Toborek M, Seelbach MJ, Rashid CS, Andras IE, Chen L, Park M, et al. Voluntary exercise protects against methamphetamine-induced oxidative stress in brain microvasculature and disruption of the blood-brain barrier. Mol Neurodegener. 2013;8:22. doi: 10.1186/17501326-8-22

[94] He XF, Liu DX, Zhang Q, Liang FY, Dai GY, Zeng JS, et al. Voluntary exercise promotes glymphatic clearance of amyloid beta and reduces the activation of astrocytes and microglia in aged mice. Front Mol Neurosci. 2017;10:144. doi: 10.3389/fnmol.2017.00144

[95] Kohman RA, Bhattacharya TK, Wojcik E, Rhodes JS. Exercise reduces activation of microglia isolated from hippocampus and brain of aged mice. J Neuroinflammation. 2013;10:114. doi: 10.1186/1742-2094-10-114

[96] Koo JH, Kang EB, Oh YS, Yang DS, Cho JY. Treadmill exercise decreases amyloid-beta burden possibly via activation of SIRT-1 signaling in a mouse model of Alzheimer's disease. Exp Neurol. 2017;288:142-52. doi: 10.1016/j.expneurol.2016.11.014

[97] Moore KM, Girens RE, Larson SK, Jones MR, Restivo JL, Holtzman DM, et al. A spectrum of exercise training reduces soluble Abeta in a dose-dependent manner in a mouse model of Alzheimer's disease. Neurobiol Dis. 2016;85:218-24. doi: 10.1016/j.nbd.2015.11.004

[98] Nichol KE, Poon WW, Parachikova AI, Cribbs DH, Glabe CG, Cotman CW. Exercise alters the immune profile in Tg2576 Alzheimer mice toward a response coincident with improved cognitive performance and decreased amyloid. J Neuroinflammation. 2008;5:13. doi: 10.1186/1742-2094-5-13

[99] Adlard PA, Perreau VM, Pop V, Cotman CW. Voluntary exercise decreases amyloid load in a transgenic model of Alzheimer's disease. J Neurosci. 2005;25:4217-21. doi: 10.1523/JNEUROSCI.0496-05.2005

[100] Zhang Y, Chao FL, Zhou CN, Jiang L, Zhang L, Chen LM, et al. Effects of exercise on capillaries in the white matter of transgenic AD mice. Oncotarget. 2017;8:65860-75. doi: 10.18632/oncotarget. 19505

[101] Kyrtsos CR, Baras JS. Modeling the Role of the Glymphatic pathway and cerebral blood vessel properties in Alzheimer's disease pathogenesis. PLoS One. 2015;10:e0139574. doi: 10.1371/journal.pone.0139574

[102] Morrone CD, Liu M, Black SE, McLaurin J. Interaction between therapeutic interventions for Alzheimer's disease and physiological Abeta clearance mechanisms. Front Aging Neurosci. 2015;7:64. doi: 10.3389/fnagi.2015.00064 
[103] Zlokovic BV. Neurovascular pathways to neurodegeneration in Alzheimer's disease and other disorders. Nat Rev Neurosci. 2011;12:723-38. doi: 10.1038/nrn3 114

[104] Obermeier B, Daneman R, Ransohoff RM. Development, maintenance and disruption of the blood-brain barrier. Nat Med. 2013;19:1584-96. doi: 10.1038/nm.3407

[105] Luissint AC, Artus C, Glacial F, Ganeshamoorthy K, Couraud PO. Tight junctions at the blood brain barrier: physiological architecture and disease-associated dysregulation. Fluids Barriers CNS. 2012;9:23. doi: 10.1186/2045-8118-9-23

[106] Morita K, Sasaki H, Furuse M, Tsukita S. Endothelial claudin: claudin-5/TMVCF constitutes tight junction strands in endothelial cells. J Cell Biol. 1999;147:185-94. doi: $10.1083 /$ jcb.147.1.185

[107] Jiao H, Wang Z, Liu Y, Wang P, Xue Y. Specific role of tight junction proteins claudin-5, occludin, and ZO-1 of the blood-brain barrier in a focal cerebral ischemic insult. J Mol Neurosci. 2011;44:130-9. doi: 10.1007/s12031-0119496-4

[108] Bolton SJ, Anthony DC, Perry VH. Loss of the tight junction proteins occludin and zonula occludens-1 from cerebral vascular endothelium during neutrophilinduced blood-brain barrier breakdown in vivo. Neuroscience. 1998;86:1245-57. doi: 10.1016/S03064522(98)00058-X

[109] Farrall AJ, Wardlaw JM. Blood-brain barrier: ageing and microvascular disease-systematic review and meta-analysis. Neurobiol Aging. 2009;30:337-52. doi: 10.1016/j.neurobiolaging.2007.07.015

[110] Elahy M, Jackaman C, Mamo JC, Lam V, Dhaliwal SS, Giles C, et al. Blood-brain barrier dysfunction developed during normal aging is associated with inflammation and loss of tight junctions but not with leukocyte recruitment. Immun Ageing. 2015;12:2. doi: 10.1186/s12979-0150029-9

[111] Erdo F, Denes L, de Lange E. Age-associated physiological and pathological changes at the blood-brain barrier: A review. J Cereb Blood Flow Metab. 2017;37:4-24. doi: 10.1177/0271678X16679420

[112] Banks WA, Erickson MA. The blood-brain barrier and immune function and dysfunction. Neurobiol Dis. 2010;37:26-32. doi: 10.1016/j.nbd.2009.07.031

[113] Hartz AM, Bauer B, Soldner EL, Wolf A, Boy S, Backhaus R, et al. Amyloid-beta contributes to bloodbrain barrier leakage in transgenic human amyloid precursor protein mice and in humans with cerebral amyloid angiopathy. Stroke. 2012;43:514-23. doi: 10.1161/STROKEAHA.111.627562

[114] Zenaro E, Piacentino G, Constantin G. The bloodbrain barrier in Alzheimer's disease. Neurobiol Dis. 2017;107:41-56. doi: 10.1016/j.nbd.2016.07.007

[115] Kalaria RN. Cerebrovascular degeneration is related to amyloid-beta protein deposition in Alzheimer's disease. Ann N Y Acad Sci. 1997;826:263-71. doi: 10.1111/j.17496632.1997.tb48478.x

[116] Kook SY, Hong HS, Moon M, Ha CM, Chang S, MookJung I. Abeta(1)(-)(4)(2)-RAGE interaction disrupts tight junctions of the blood-brain barrier via $\mathrm{Ca}(2)(+)-$ calcineurin signaling. J Neurosci. 2012;32:8845-54. doi: 10.1523/JNEUROSCI.6102-11.2012

[117] Kook SY, Seok Hong H, Moon M, Mook-Jung I. Disruption of blood-brain barrier in Alzheimer disease pathogenesis. Tissue Barriers. 2013;1:e23993. doi: 10.4161/tisb.23993
[118] Sweeney MD, Sagare AP, Zlokovic BV. Blood-brain barrier breakdown in Alzheimer disease and other neurodegenerative disorders. Nat Rev Neurol. 2018;14:133-50. doi: 10.1038/nrneurol.2017.188

[119] Ulrich JD, Huynh TP, Holtzman DM. Re-evaluation of the Blood-Brain Barrier in the Presence of Alzheimer's Disease Pathology. Neuron. 2015;88:237-9. doi: 10.1016/j.neuron.2015.10.008

[120] Swardfager W, Lanctot K, Rothenburg L, Wong A, Cappell $\mathrm{J}$, Herrmann N. A meta-analysis of cytokines in Alzheimer's disease. Biol Psychiatry. 2010;68:930-41. doi: 10.1016/j.biopsych.2010.06.012

[121] Bell RD, Winkler EA, Singh I, Sagare AP, Deane R, $\mathrm{Wu} \mathrm{Z}$, et al. Apolipoprotein E controls cerebrovascular integrity via cyclophilin A. Nature. 2012;485:512-6. doi: $10.1038 /$ nature 11087

[122] Zlokovic BV. Cerebrovascular effects of apolipoprotein E: implications for Alzheimer disease. JAMA Neurol. 2013;70:440-4. doi: 10.1001/jamaneurol.2013.2152

[123] Kim J, Basak JM, Holtzman DM. The role of apolipoprotein E in Alzheimer's disease. Neuron. 2009;63:287-303. doi: 10.1016/j.neuron.2009.06.026

[124] Liu CC, Liu CC, Kanekiyo T, Xu H, Bu G. Apolipoprotein $\mathrm{E}$ and Alzheimer disease: risk, mechanisms and therapy. Nat Rev Neurol. 2013;9:106-18. doi: 10.1038/nrneurol.2012.263

[125] Buttler L, Jordao MT, Fragas MG, Ruggeri A, Ceroni A, Michelini LC. Maintenance of Blood-Brain Barrier Integrity in Hypertension: A Novel Benefit of Exercise Training for Autonomic Control. Front Physiol. 2017;8:1048. doi: 10.3389/fphys.2017.01048

[126] Biancardi VC, Son SJ, Ahmadi S, Filosa JA, Stern JE. Circulating angiotensin II gains access to the hypothalamus and brain stem during hypertension via breakdown of the blood-brain barrier. Hypertension. 2014;63:572-9. doi: 10.1161/HYPERTENSIONAHA.113.01743

[127] Biancardi VC, Stern JE. Compromised blood-brain barrier permeability: novel mechanism by which circulating angiotensin II signals to sympathoexcitatory centres during hypertension. J Physiol. 2016;594:1591-600. doi: 10.1113/JP271584

[128] Pelisch N, Hosomi N, Mori H, Masaki T, Nishiyama A. RAS inhibition attenuates cognitive impairment by reducing blood- brain barrier permeability in hypertensive subjects. Curr Hypertens Rev. 2013;9:93-8.

[129] Pelisch N, Hosomi N, Ueno M, Nakano D, Hitomi H, Mogi $\mathrm{M}$, et al. Blockade of AT1 receptors protects the bloodbrain barrier and improves cognition in Dahl salt-sensitive hypertensive rats. Am J Hypertens. 2011;24:362-8. doi: 10.1038/ajh.2010.241

[130] Zhang Y, Zhang P, Shen X, Tian S, Wu Y, Zhu Y, et al. Early exercise protects the blood-brain barrier from ischemic brain injury via the regulation of MMP-9 and occludin in rats. Int J Mol Sci. 2013;14:11096-112. doi: 10.3390/ijms 140611096

[131] Guo M, Cox B, Mahale S, Davis W, Carranza A, Hayes K, et al. Pre-ischemic exercise reduces matrix metalloproteinase-9 expression and ameliorates blood-brain barrier dysfunction in stroke. Neuroscience. 2008;151:340-51. doi: 10.1016/j.neuroscience.2007.10. 006

[132] Wolff G, Davidson SJ, Wrobel JK, Toborek M. Exercise maintains blood-brain barrier integrity during early stages of brain metastasis formation. Biochem Biophys Res Commun. 2015;463:811-7. doi: 10.1016/j.bbrc.2015.04.153 
[133] Mestre H, Kostrikov S, Mehta RI, Nedergaard M. Perivascular spaces, glymphatic dysfunction, and small vessel disease. Clin Sci (Lond). 2017;131:2257-74. doi: 10.1042/CS20160381

[134] Gaberel T, Gakuba C, Goulay R, Martinez De Lizarrondo S, Hanouz JL, Emery E, et al. Impaired glymphatic perfusion after strokes revealed by contrast-enhanced MRI: a new target for fibrinolysis? Stroke. 2014;45:3092-6. doi: 10.1161/STROKEAHA.114.006617

[135] Siler DA, Gonzalez JA, Wang RK, Cetas JS, Alkayed NJ. Intracisternal administration of tissue plasminogen activator improves cerebrospinal fluid flow and cortical perfusion after subarachnoid hemorrhage in mice. Transl Stroke Res. 2014;5:227-37. doi: 10.1007/s12975014-0329-y

[136] Xie L, Kang H, Xu Q, Chen MJ, Liao Y, Thiyagarajan M, et al. Sleep drives metabolite clearance from the adult brain. Science. 2013;342:373-7. doi: 10.1126/science. 1241224

[137] Wardlaw JM, Smith EE, Biessels GJ, Cordonnier C, Fazekas F, Frayne R, et al. Neuroimaging standards for research into small vessel disease and its contribution to ageing and neurodegeneration. Lancet Neurol. 2013;12:822-38. doi: 10.1016/S1474-4422(13)701 24-8

[138] Wuerfel J, Haertle M, Waiczies H, Tysiak E, Bechmann I, Wernecke KD, et al. Perivascular spaces-MRI marker of inflammatory activity in the brain? Brain. 2008;131:233240. doi: 10.1093/brain/awn171

[139] Verheggen ICM, Van Boxtel MPJ, Verhey FRJ, Jansen JFA, Backes WH. Interaction between bloodbrain barrier and glymphatic system in solute clearance. Neurosci Biobehav Rev. 2018;90:26-33. doi: 10.1016/j.neubiorev.2018.03.028

[140] Kress BT, Iliff JJ, Xia M, Wang M, Wei HS, Zeppenfeld $\mathrm{D}$, et al. Impairment of paravascular clearance pathways in the aging brain. Ann Neurol. 2014;76:845-61. doi: 10.1002/ana.24271

[141] Peng W, Achariyar TM, Li B, Liao Y, Mestre H, Hitomi E, et al. Suppression of glymphatic fluid transport in a mouse model of Alzheimer's disease. Neurobiol Dis. 2016;93:215-25. doi: 10.1016/j.nbd.2016.05.015

[142] Carare RO, Bernardes-Silva M, Newman TA, Page AM, Nicoll JA, Perry VH, et al. Solutes, but not cells, drain from the brain parenchyma along basement membranes of capillaries and arteries: significance for cerebral amyloid angiopathy and neuroimmunology. Neuropathol Appl Neurobiol. 2008;34:131-44. doi: 10.1111/j.13652990.2007.00926.x

[143] Iliff JJ, Wang M, Liao Y, Plogg BA, Peng W, Gundersen GA, et al. A paravascular pathway facilitates CSF flow through the brain parenchyma and the clearance of interstitial solutes, including amyloid beta. Sci Transl Med. 2012;4:147ra11. doi: 10.1126/scitranslmed. 3003748

[144] Abbott NJ, Pizzo ME, Preston JE, Janigro D, Thorne RG. The role of brain barriers in fluid movement in the CNS: is there a 'glymphatic' system? Acta Neuropathol. 2018;135:387-407. doi: 10.1007/s00401-018-1812-4

[145] von Holstein-Rathlou S, Petersen NC, Nedergaard M. Voluntary running enhances glymphatic influx in awake behaving, young mice. Neurosci Lett. 2018;662:253-8. doi: 10.1016/j.neulet.2017.10.035

[146] Ambree O, Leimer U, Herring A, Gortz N, Sachser $\mathrm{N}$, Heneka MT, et al. Reduction of amyloid angiopa- thy and Abeta plaque burden after enriched housing in TgCRND8 mice: involvement of multiple pathways. Am J Pathol. 2006;169:544-52. doi: 10.2353/ajpath.2006. 051107

[147] Tapia-Rojas C, Aranguiz F, Varela-Nallar L, Inestrosa NC. Voluntary running attenuates memory loss, decreases neuropathological changes and induces neurogenesis in a mouse model of Alzheimer's disease. Brain Pathol. 2016;26:62-74. doi: 10.1111/bpa.12255

[148] Yuede CM, Zimmerman SD, Dong H, Kling MJ, Bero AW, Holtzman DM, et al. Effects of voluntary and forced exercise on plaque deposition, hippocampal volume, and behavior in the Tg2576 mouse model of Alzheimer's disease. Neurobiol Dis. 2009;35:426-32. doi: 10.1016/j.nbd.2009.06.002

[149] Jope RS, Johnson GV. The glamour and gloom of glycogen synthase kinase-3. Trends Biochem Sci. 2004;29:95-102. doi: 10.1016/j.tibs.2003.12.004

[150] Liu HL, Zhao G, Zhang H, Shi LD. Long-term treadmill exercise inhibits the progression of Alzheimer's diseaselike neuropathology in the hippocampus of APP/PS1 transgenic mice. Behav Brain Res. 2013;256:261-72. doi: 10.1016/j.bbr.2013.08.008

[151] Prado Lima MG, Schimidt HL, Garcia A, Dare LR, Carpes FP, Izquierdo I, et al. Environmental enrichment and exercise are better than social enrichment to reduce memory deficits in amyloid beta neurotoxicity. Proc Natl Acad Sci U S A. 2018. doi: 10.1073/pnas.1718435115

[152] Um HS, Kang EB, Leem YH, Cho IH, Yang CH, Chae KR, et al. Exercise training acts as a therapeutic strategy for reduction of the pathogenic phenotypes for Alzheimer's disease in an NSE/APPsw-transgenic model. Int $\mathbf{J}$ Mol Med. 2008;22:529-39.

[153] Rattiner LM, Davis M, French CT, Ressler KJ. Brain-derived neurotrophic factor and tyrosine kinase receptor B involvement in amygdala-dependent fear conditioning. J Neurosci. 2004;24:4796-806. doi: 10.1523/JNEUROSCI.5654-03.2004

[154] Revilla S, Sunol C, Garcia-Mesa Y, Gimenez-Llort L, Sanfeliu C, Cristofol R. Physical exercise improves synaptic dysfunction and recovers the loss of survival factors in $3 x T g-A D$ mouse brain. Neuropharmacology. 2014;81:5563. doi: 10.1016/j.neuropharm.2014.01.037

[155] Richter H, Ambree O, Lewejohann L, Herring A, Keyvani K, Paulus W, et al. Wheel-running in a transgenic mouse model of Alzheimer's disease: protection or symptom? Behav Brain Res. 2008;190:74-84. doi: 10.1016/j.bbr.2008.02.005

[156] Rolland Y, Abellan van Kan G, Vellas B. Physical activity and Alzheimer's disease: from prevention to therapeutic perspectives. J Am Med Dir Assoc. 2008;9:390-405. doi: 10.1016/j.jamda.2008.02.007

[157] Rolland Y, Pillard F, Klapouszczak A, Reynish E, Thomas $\mathrm{D}$, Andrieu S, et al. Exercise program for nursing home residents with Alzheimer's disease: a 1-year randomized, controlled trial. J Am Geriatr Soc. 2007;55:158-65. doi: 10.1111/j.1532-5415.2007.01035.x

[158] Kang H, Schuman EM. Long-lasting neurotrophininduced enhancement of synaptic transmission in the adult hippocampus. Science. 1995;267:1658-62. doi: $10.1126 /$ science.7886457

[159] Kang H, Welcher AA, Shelton D, Schuman EM. Neurotrophins and time: different roles for TrkB signaling in hippocampal long-term potentiation. Neuron. 1997;19:653-64. doi: 10.1016/S0896-6273(00)80378-5 
[160] Levine ES, Dreyfus CF, Black IB, Plummer MR. Brainderived neurotrophic factor rapidly enhances synaptic transmission in hippocampal neurons via postsynaptic tyrosine kinase receptors. Proc Natl Acad Sci U S A. 1995;92:8074-7. doi: 10.1073/pnas.92.17.8074

[161] Yoshii A, Constantine-Paton M. BDNF induces transport of PSD-95 to dendrites through PI3K-AKT signaling after NMDA receptor activation. Nat Neurosci. 2007;10:70211. doi: $10.1038 / \mathrm{nn} 1903$

[162] Bednarek E, Caroni P. beta-Adducin is required for stable assembly of new synapses and improved memory upon environmental enrichment. Neuron. 2011;69:113246. doi: 10.1016/j.neuron.2011.02.034

[163] Ma Z, Zang T, Birnbaum SG, Wang Z, Johnson JE, Zhang CL, et al. TrkB dependent adult hippocampal progenitor differentiation mediates sustained ketamine antidepressant response. Nat Commun. 2017;8:1668. doi: 10.1038/s41467-017-01709-8

[164] Lau D, Bengtson CP, Buchthal B, Bading H. BDNF Reduces Toxic Extrasynaptic NMDA Receptor Signaling via Synaptic NMDA Receptors and NuclearCalcium-Induced Transcription of inhba/Activin A. Cell Rep. 2015;12:1353-66. doi: 10.1016/j.celrep.2015. 07.038

[165] Li Y, Luikart BW, Birnbaum S, Chen J, Kwon CH, Kernie $\mathrm{SG}$, et al. TrkB regulates hippocampal neurogenesis and governs sensitivity to antidepressive treatment. Neuron. 2008;59:399-412. doi: 10.1016/j.neuron.2008.06.023

[166] Waterhouse EG, An JJ, Orefice LL, Baydyuk M, Liao $\mathrm{GY}$, Zheng $\mathrm{K}$, et al. BDNF promotes differentiation and maturation of adult-born neurons through GABAergic transmission. J Neurosci. 2012;32:14318-30. doi: 10.1523/JNEUROSCI.0709-12.2012

[167] Danzer SC, Crooks KR, Lo DC, McNamara JO. Increased expression of brain-derived neurotrophic factor induces formation of basal dendrites and axonal branching in dentate granule cells in hippocampal explant cultures. J Neurosci. 2002;22:9754-63. doi: 10.1523/JNEUROSCI.22-22-09754.2002

[168] Russo-Neustadt AA, Chen MJ. Brain-derived neurotrophic factor and antidepressant activity. Curr Pharm Des. 2005;11:1495-510. doi: $10.2174 / 1381612053764788$

[169] Figurov A, Pozzo-Miller LD, Olafsson P, Wang T, Lu B. Regulation of synaptic responses to high-frequency stimulation and LTP by neurotrophins in the hippocampus. Nature. 1996;381:706-9. doi: 10.1038/381706a0

[170] Ma YL, Wang HL, Wu HC, Wei CL, Lee EH. Brain-derived neurotrophic factor antisense oligonucleotide impairs memory retention and inhibits long-term potentiation in rats. Neuroscience. 1998;82:957-67. doi: 10.1016/S0306-4522(97)00325-4

[171] Atwal JK, Massie B, Miller FD, Kaplan DR. The TrkBShc site signals neuronal survival and local axon growth via MEK and P13-kinase. Neuron. 2000;27:265-77. doi: 10.1016/S0896-6273(00)00035-0

[172] Heldt SA, Stanek L, Chhatwal JP, Ressler KJ. Hippocampus-specific deletion of BDNF in adult mice impairs spatial memory and extinction of aversive memories. Mol Psychiatry. 2007;12:656-70. doi: 10.1038/sj.mp.4001957

[173] Fahnestock M. Brain-derived neurotrophic factor: the link between amyloid-beta and memory loss. Future Neurology. 2011;6:627-39. doi: 10.2217/fnl.11.44
[174] Peng S, Garzon DJ, Marchese M, Klein W, Ginsberg $\mathrm{SD}$, Francis BM, et al. Decreased brain-derived neurotrophic factor depends on amyloid aggregation state in transgenic mouse models of Alzheimer's disease. J Neurosci. 2009;29:9321-9. doi: 10.1523/JNEUROSCI.473608.2009

[175] Peng S, Wuu J, Mufson EJ, Fahnestock M. Precursor form of brain-derived neurotrophic factor and mature brain-derived neurotrophic factor are decreased in the pre-clinical stages of Alzheimer's disease. J Neurochem. 2005;93:1412-21. doi: 10.1111/j.14714159.2005.03135.x

[176] Webster MJ, Herman MM, Kleinman JE, Shannon Weickert C. BDNF and trkB mRNA expression in the hippocampus and temporal cortex during the human lifespan. Gene Expr Patterns. 2006;6:941-51. doi: 10.1016/j.modgep.2006.03.009

[177] Garzon D, Yu G, Fahnestock M. A new brain-derived neurotrophic factor transcript and decrease in brain-derived neurotrophic factor transcripts 1, 2 and 3 in Alzheimer's disease parietal cortex. J Neurochem. 2002;82:1058-64. doi: 10.1046/j.1471-4159.2002.01030.x

[178] Garzon DJ, Fahnestock M. Oligomeric amyloid decreases basal levels of brain-derived neurotrophic factor (BDNF) mRNA via specific downregulation of BDNF transcripts IV and $\mathrm{V}$ in differentiated human neuroblastoma cells. J Neurosci. 2007;27:2628-35. doi: 10.1523/JNEUROSCI. 5053-06.2007

[179] Devi L, Ohno M. TrkB reduction exacerbates Alzheimer's disease-like signaling aberrations and memory deficits without affecting beta-amyloidosis in 5XFAD mice. Transl Psychiatry. 2015;5:e562. doi: 10.1038/tp.2015.55

[180] Marosi K, Mattson MP. BDNF mediates adaptive brain and body responses to energetic challenges. Trends Endocrinol Metab. 2014;25:89-98. doi: 10.1016/j.tem.2013.10.006

[181] Rothman SM, Griffioen KJ, Wan R, Mattson MP. Brainderived neurotrophic factor as a regulator of systemic and brain energy metabolism and cardiovascular health. Ann N Y Acad Sci. 2012;1264:49-63. doi: 10.1111/j.17496632.2012.06525.x

[182] Szuhany KL, Bugatti M, Otto MW. A meta-analytic review of the effects of exercise on brain-derived neurotrophic factor. J Psychiatr Res. 2015;60:56-64. doi: 10.1016/j.jpsychires.2014.10.003

[183] Dinoff A, Herrmann N, Swardfager W, Liu CS, Sherman C, Chan S, et al. The Effect of Exercise Training on Resting Concentrations of Peripheral Brain-Derived Neurotrophic Factor (BDNF): A Meta-Analysis. PLoS One. 2016;11:e0163037. doi: 10.1371/journal.pone.0163 037

[184] Chen MJ, Russo-Neustadt AA. Running exercise-induced up-regulation of hippocampal brain-derived neurotrophic factor is CREB-dependent. Hippocampus. 2009;19:96272. doi: 10.1002/hipo.20579

[185] Adlard PA, Perreau VM, Engesser-Cesar C, Cotman CW. The timecourse of induction of brain-derived neurotrophic factor mRNA and protein in the rat hippocampus following voluntary exercise. Neurosci Lett. 2004;363:43-8. doi: 10.1016/j.neulet.2004.03.058

[186] Farmer J, Zhao X, van Praag H, Wodtke K, Gage FH, Christie BR. Effects of voluntary exercise on synaptic plasticity and gene expression in the dentate gyrus of adult male Sprague-Dawley rats in vivo. Neuroscience. 2004;124:71-9. doi: 10.1016/j.neuroscience.2003.09.029 
[187] Griffin EW, Bechara RG, Birch AM, Kelly AM. Exercise enhances hippocampal-dependent learning in the rat: evidence for a BDNF-related mechanism. Hippocampus. 2009;19:973-80. doi: 10.1002/hipo.20631

[188] Garza AA, Ha TG, Garcia C, Chen MJ, Russo-Neustadt AA. Exercise, antidepressant treatment, and BDNF mRNA expression in the aging brain. Pharmacol Biochem Behav. 2004;77:209-20. doi: 10.1016/j.pbb.2003.10.020

[189] Ivy AS, Rodriguez FG, Garcia C, Chen MJ, RussoNeustadt AA. Noradrenergic and serotonergic blockade inhibits BDNF mRNA activation following exercise and antidepressant. Pharmacol Biochem Behav. 2003;75:81-8. doi: 10.1016/S0091-3057(03)00044-3

[190] Neeper SA, Gomez-Pinilla F, Choi J, Cotman CW. Physical activity increases mRNA for brain-derived neurotrophic factor and nerve growth factor in rat brain. Brain Res. 1996;726:49-56. doi: 10.1016/0006-8993(96) 00273-9

[191] Russo-Neustadt A, Beard RC, Cotman CW. Exercise, antidepressant medications, and enhanced brain derived neurotrophic factor expression. Neuropsychopharmacology. 1999;21:679-82. doi: 10.1016/S0893133X(99)00059-7

[192] Sleiman SF, Henry J, Al-Haddad R, El Hayek L, Abou Haidar E, Stringer T, et al. Exercise promotes the expression of brain derived neurotrophic factor (BDNF) through the action of the ketone body beta-hydroxybutyrate. Elife. 2016;5. doi: 10.7554/eLife.15092

[193] Carro E, Trejo JL, Busiguina S, Torres-Aleman I. Circulating insulin-like growth factor I mediates the protective effects of physical exercise against brain insults of different etiology and anatomy. J Neurosci. 2001;21:5678-84. doi: 10.1523/JNEUROSCI.21-15-05678.2001

[194] Yamanashi T, Iwata M, Kamiya N, Tsunetomi K, Kajitani N, Wada N, et al. Beta-hydroxybutyrate, an endogenic NLRP3 inflammasome inhibitor, attenuates stress-induced behavioral and inflammatory responses. Sci Rep. 2017;7:7677. doi: 10.1038/s41598-017-08055-1

[195] Nehlig A. Brain uptake and metabolism of ketone bodies in animal models. Prostaglandins Leukot Essent Fatty Acids. 2004;70:265-75. doi: 10.1016/j.plefa.2003.07.006

[196] Pierre K, Pellerin L. Monocarboxylate transporters in the central nervous system: distribution, regulation and function. J Neurochem. 2005;94:1-14. doi: 10.1111/j.1471-4159.2005.03168.x

[197] Portela LV, Brochier AW, Haas CB, de Carvalho AK, Gnoato JA, Zimmer ER, et al. Hyperpalatable Diet and Physical Exercise Modulate the Expression of the Glial Monocarboxylate Transporters MCT1 and 4. Mol Neurobiol. 2017;54:5807-14. doi: 10.1007/s12035-0160119-5

[198] Regen DM, Callis JT, Sugden MC. Studies of cerebral beta-hydroxybutyrate transport by carotid injection; effects of age, diet and injectant composition. Brain Res. 1983;271:289-99. doi: 10.1016/0006-8993(83)90291-3

[199] Shima T, Matsui T, Jesmin S, Okamoto M, Soya M, Inoue $\mathrm{K}$, et al. Moderate exercise ameliorates dysregulated hippocampal glycometabolism and memory function in a rat model of type 2 diabetes. Diabetologia. 2017;60:597-606. doi: 10.1007/s00125-016-4164-4

[200] Sonntag WE, Bennett SA, Khan AS, Thornton PL, $\mathrm{Xu} \mathrm{X}$, Ingram RL, et al. Age and insulin-like growth factor-1 modulate N-methyl-D-aspartate receptor subtype expression in rats. Brain Res Bull. 2000;51:331-8. doi: 10.1016/S0361-9230(99)00259-2
[201] Berchtold NC, Castello N, Cotman CW. Exercise and time-dependent benefits to learning and memory. Neuroscience. 2010;167:588-97. doi: 10.1016/j.neuroscience.2010.02.050

[202] Berchtold NC, Chinn G, Chou M, Kesslak JP, Cotman CW. Exercise primes a molecular memory for brain-derived neurotrophic factor protein induction in the rat hippocampus. Neuroscience. 2005;133:853-61. doi: 10.1016/j.neuroscience.2005.03.026

[203] Berchtold NC, Kesslak JP, Cotman CW. Hippocampal brain-derived neurotrophic factor gene regulation by exercise and the medial septum. J Neurosci Res. 2002;68:511-21. doi: 10.1002/jnr. 10256

[204] Lee M, Soya H. Effects of acute voluntary loaded wheel running on BDNF expression in the rat hippocampus. J Exerc Nutrition Biochem. 2017;21:52-7. doi: 10.20463/jenb.2017.0034

[205] Ang ET, Wong PT, Moochhala S, Ng YK. Neuroprotection associated with running: is it a result of increased endogenous neurotrophic factors? Neuroscience. 2003;118:33545. doi: 10.1016/S0306-4522(02)00989-2

[206] Chen J, Qin J, Su Q, Liu Z, Yang J. Treadmill rehabilitation treatment enhanced BDNF-TrkB but not NGF-TrkA signaling in a mouse intracerebral hemorrhage model. Neurosci Lett. 2012;529:28-32. doi: 10.1016/j.neulet.2012.09.021

[207] Maliszewska-Cyna E, Lynch M, Oore JJ, Nagy PM, Aubert I. The benefits of exercise and metabolic interventions for the prevention and early treatment of Alzheimer's disease. Curr Alzheimer Res. 2017;14:47-60. doi: 10.2174/1567205013666160819125400

[208] Zhao Z, Nelson AR, Betsholtz C, Zlokovic BV. Establishment and dysfunction of the blood-brain barrier. Cell. 2015;163:1064-78. doi: 10.1016/j.cell.2015.10.067

[209] Pan W, Kastin AJ. Interactions of IGF-1 with the bloodbrain barrier in vivo and in situ. Neuroendocrinology. 2000;72:171-8. doi: 10.1159/000054584

[210] Baek SS. Role of exercise on the brain. J Exerc Rehabil. 2016;12:380-5. doi: 10.12965/jer.1632808.404

[211] Sonntag WE, Deak F, Ashpole N, Toth P, Csiszar A, Freeman W, et al. Insulin-like growth factor-1 in CNS and cerebrovascular aging. Front Aging Neurosci. 2013;5:27. doi: 10.3389/fnagi.2013.00027

[212] Berg U, Bang P. Exercise and circulating insulin-like growth factor I. Horm Res. 2004;62 Suppl 1:50-8. doi: 10.1159/000080759

[213] Cappon J, Brasel JA, Mohan S, Cooper DM. Effect of brief exercise on circulating insulin-like growth factor I. J Appl Physiol (1985). 1994;76:2490-6. doi: 10.1152/jappl.1994.76.6.2490

[214] Prior SJ, Jenkins NT, Brandauer J, Weiss EP, Hagberg JM. Aerobic exercise training increases circulating insulin-like growth factor binding protein-1 concentration, but does not attenuate the reduction in circulating insulin-like growth factor binding protein-1 after a high-fat meal. Metabolism. 2012;61:310-6. doi: 10.1016/j.metabol.2011.07.003

[215] Park JS, Hoke A. Treadmill exercise induced functional recovery after peripheral nerve repair is associated with increased levels of neurotrophic factors. PLoS One. 2014;9:e90245. doi: 10.1371/journal.pone.0090245

[216] Cao Y, Gunn AJ, Bennet L, Wu D, George S, Gluckman PD, et al. Insulin-like growth factor (IGF)-1 suppresses oligodendrocyte caspase-3 activation and increases glial proliferation after ischemia in near-term 
fetal sheep. J Cereb Blood Flow Metab. 2003;23:739-47. doi: 10.1097/01.WCB.0000067720.12805.6F

[217] Guan J, Gunn AJ, Sirimanne ES, Tuffin J, Gunning MI, Clark R, et al. The window of opportunity for neuronal rescue with insulin-like growth factor-1 after hypoxia-ischemia in rats is critically modulated by cerebral temperature during recovery. J Cereb Blood Flow Metab. 2000;20:513-9. doi: 10.1097/00004647200003000-00010

[218] Guan J, Miller OT, Waugh KM, McCarthy DC, Gluckman PD. Insulin-like growth factor-1 improves somatosensory function and reduces the extent of cortical infarction and ongoing neuronal loss after hypoxiaischemia in rats. Neuroscience. 2001;105:299-306. doi: doi.org/10.1016/S0306-4522(01)00145-2

[219] Sizonenko SV, Sirimanne ES, Williams CE, Gluckman PD. Neuroprotective effects of the N-terminal tripeptide of IGF-1, glycine-proline-glutamate, in the immature rat brain after hypoxic-ischemic injury. Brain Res. 2001;922:42-50. doi: 10.1016/S0006-8993(01)03148-1

[220] Sonntag WE, Lynch C, Thornton P, Khan A, Bennett $S$, Ingram $R$. The effects of growth hormone and IGF-1 deficiency on cerebrovascular and brain ageing. J Anat. 2000;197 Pt 4:575-85. doi: 10.1046/j.14697580.2000.19740575.x

[221] Li Y, Sun W, Han S, Li J, Ding S, Wang W, et al. IGF1-involved negative feedback of NR2B NMDA subunits protects cultured hippocampal neurons against NMDAInduced excitotoxicity. Mol Neurobiol. 2017;54:684-96. doi: 10.1007/s12035-015-9647-7

[222] Lin T-W, Kuo Y-M. Exercise benefits brain function: The monoamine connection. Brain Sciences. 2013;3:39-53. doi: 10.3390/brainsci3010039

[223] Cohen Z, Bonvento G, Lacombe P, Hamel E. Serotonin in the regulation of brain microcirculation. Prog Neurobiol. 1996;50:335-62. doi: 10.1016/S0301-0082(96)00033-0

[224] Engleton RP, Abbruscato T. Drug abuse and the neurovascular unit. In: Davis TP, editor. Advances in pharmacology Volume seventy one, Pharmacology of the blood brain barrier targeting CNS disorders. First edition. ed. London, England: Academic Press; 2014. p. 451-80. doi: 10.1016/bs.apha.2014.06.019

[225] McMorris T. Developing the catecholamines hypothesis for the acute exercise-cognition interaction in humans: Lessons from animal studies. Physiology \& Behavior. 2016;165:291-9. doi: 10.1016/j.physbeh.2016.08.011

[226] Meeusen R, De Meirleir K. Exercise and brain neurotransmission. Sports Med. 1995;20:160-88. doi: 10.2165/00007256-199520030-00004

[227] Meeusen R, Piacentini MF, De Meirleir K. Brain microdialysis in exercise research. Sports Med. 2001;31:965-83. doi: 10.2165/00007256-200131140-00002

[228] Elhusseiny A, Hamel E. Muscarinic-but not nicotinicacetylcholine receptors mediate a nitric oxide-dependent dilation in brain cortical arterioles: a possible role for the M5 receptor subtype. J Cereb Blood Flow Metab. 2000;20:298-305. doi: 10.1097/00004647-20000200000011

[229] Hamel E. Perivascular nerves and the regulation of cerebrovascular tone. J Appl Physiol (1985). 2006;100:105964. doi: 10.1152/japplphysiol.00954.2005

[230] Serrador JM, Freeman R. Enhanced cholinergic activity improves cerebral blood flow during orthostatic stress. Front Neurol. 2017;8:103. doi: 10.3389/fneur. 2017.00103
[231] Smith KJ, Ainslie PN. Regulation of cerebral blood flow and metabolism during exercise. Exp Physiol. 2017;102:1356-71. doi: 10.1113/EP086249

[232] Nibuya M, Morinobu S, Duman RS. Regulation of BDNF and trkB mRNA in rat brain by chronic electroconvulsive seizure and antidepressant drug treatments. J Neurosci. 1995;15:7539-47. doi: 10.1523/JNEUROSCI.1511-07539.1995

[233] O’Dell TJ, Connor SA, Guglietta R, Nguyen PV. Adrenergic receptor signaling and modulation of long-term potentiation in the mammalian hippocampus. Learn Mem. 2015;22:461-71. doi:10.1101/lm.031088.113

[234] Garcia C, Chen MJ, Garza AA, Cotman CW, RussoNeustadt A. The influence of specific noradrenergic and serotonergic lesions on the expression of hippocampal brain-derived neurotrophic factor transcripts following voluntary physical activity. Neuroscience. 2003;119:72132. doi: 10.1016/S0306-4522(03)00192-1

[235] Kellner Y, Godecke N, Dierkes T, Thieme N, Zagrebelsky M, Korte M. The BDNF effects on dendritic spines of mature hippocampal neurons depend on neuronal activity. Front Synaptic Neurosci. 2014;6:5. doi: 10.3389/fnsyn.2014.00005

[236] Vasuta C, Caunt C, James R, Samadi S, Schibuk E, Kannangara $\mathrm{T}$, et al. Effects of exercise on NMDA receptor subunit contributions to bidirectional synaptic plasticity in the mouse dentate gyrus. Hippocampus. 2007;17:1201-8. doi: 10.1002/hipo.20349

[237] Uchida S, Suzuki A, Kagitani F, Hotta H. Responses of acetylcholine release and regional blood flow in the hippocampus during walking in aged rats. J Physiol Sci. 2006;56:253-7. doi: 10.2170/physiolsci.SC001706

[238] Knipper M, da Penha Berzaghi M, Blochl A, Breer $\mathrm{H}$, Thoenen H, Lindholm D. Positive feedback between acetylcholine and the neurotrophins nerve growth factor and brain-derived neurotrophic factor in the rat hippocampus. Eur J Neurosci. 1994;6:668-71. doi: 10.1111/j.1460-9568.1994.tb00312.x

[239] Heo YM, Shin MS, Lee JM, Kim CJ, Baek SB, Kim KH, et al. Treadmill exercise ameliorates short-term memory disturbance in scopolamine-induced amnesia rats. Int Neurourol J. 2014;18:16-22. doi: 10.5213/inj.2014.18.1.16

[240] Giocomo LM, Hasselmo ME. Neuromodulation by glutamate and acetylcholine can change circuit dynamics by regulating the relative influence of afferent input and excitatory feedback. Mol Neurobiol. 2007;36:184-200. doi: 10.1007/s12035-007-0032-z

[241] Hill LE, Droste SK, Nutt DJ, Linthorst AC, Reul JM. Voluntary exercise alters GABA(A) receptor subunit and glutamic acid decarboxylase-67 gene expression in the rat forebrain. J Psychopharmacol. 2010;24:745-56. doi: 10.1177/0269881108096983

[242] Ota M, Yasuno F, Ito H, Seki C, Nozaki S, Asada T, et al. Age-related decline of dopamine synthesis in the living human brain measured by positron emission tomography with 1-[ $\beta-11 C] D O P A$. Life Sci. 2006;79:730-6. doi: 10.1016/j.lfs.2006.02.017

[243] Iyo M. The detection of age-related decrease of dopamine D1, D2 and serotonin 5-HT2 receptors in living human brain. Prog Neuropsychopharmacol Biol Pschiatry. 2002;17(3):415-21

[244] Peters R. Ageing and the brain. Postgrad Med J. 2006;82:84-8. doi: 10.1136/pgmj.2005.036665

[245] Wong DF, Wagner HN, Jr., Dannals RF, Links JM, Frost JJ, Ravert HT, et al. Effects of age on dopamine and serotonin 
receptors measured by positron tomography in the living human brain. Science. 1984;226:1393-6. doi: 10.1126/science.6334363

[246] Wu SY, Wang TF, Yu L, Jen CJ, Chuang JI, Wu FS, et al. Running exercise protects the substantia nigra dopaminergic neurons against inflammation-induced degeneration via the activation of BDNF signaling pathway. Brain Behav Immun. 2011;25:135-46. doi: 10.1016/j.bbi.2010.09.006

[247] Hasbi A, Fan T, Alijaniaram M, Nguyen T, Perreault ML, O'Dowd BF, et al. Calcium signaling cascade links dopamine D1-D2 receptor heteromer to striatal BDNF production and neuronal growth. Proc Natl Acad Sci U S A. 2009;106:21377-82. doi: 10.1073/pnas.0903676106

[248] Iwakura Y, Nawa H, Sora I, Chao MV. Dopamine D1 receptor-induced signaling through TrkB receptors in striatal neurons. J Biol Chem. 2008;283:15799-806. doi: 10.1074/jbc.M801553200

[249] Do T, Kerr B, Kuzhikandathil EV. Brain-derived neurotrophic factor regulates the expression of D1 dopamine receptors. J Neurochem. 2007;100:416-28. doi: 10.1111/j.1471-4159.2006.04249.x

[250] Guillin O, Diaz J, Carroll P, Griffon N, Schwartz JC, Sokoloff P. BDNF controls dopamine D3 receptor expression and triggers behavioural sensitization. Nature. 2001;411:86-9. doi: 10.1038/35075076

[251] Fisher BE, Li Q, Nacca A, Salem GJ, Song J, Yip $\mathrm{J}$, et al. Treadmill exercise elevates striatal dopamine D2 receptor binding potential in patients with early Parkinson's disease. NeuroReport. 2013;24:509-14. doi: 10.1097/WNR.0b013e328361dc13

[252] Petzinger GM, Walsh JP, Akopian G, Hogg E, Abernathy A, Arevalo P, et al. Effects of treadmill exercise on dopaminergic transmission in the 1-methyl-4-phenyl1,2,3,6-tetrahydropyridine-lesioned mouse model of basal ganglia injury. J Neurosci. 2007;27:5291-300. doi: 10.1523/JNEUROSCI.1069-07.2007

[253] Gilliam PE, Spirduso WW, Martin TP, Walters TJ, Wilcox RE, Farrar RP. The effects of exercise training on $[3 \mathrm{H}]$-spiperone binding in rat striatum. Pharmacol Biochem Behav. 1984;20:863-7. doi: 10.1016/00913057(84)90008-X

[254] MacRae PG, Spirduso WW, Cartee GD, Farrar RP, Wilcox RE. Endurance training effects on striatal D2 dopamine receptor binding and striatal dopamine metabolite levels. Neurosci Lett. 1987;79:138-44. doi: 10.1016/0304-3940(87)90686-0

[255] Mathes WF, Nehrenberg DL, Gordon R, Hua K, Garland Jr T, Pomp D. Dopaminergic dysregulation in mice selectively bred for excessive exercise or obesity. Behav Brain Res. 2010;210:155-63. doi: 10.1016/j.bbr.2010.02.016

[256] Sutoo De, Akiyama K. Regulation of brain function by exercise. Neurobiol Dis. 2003;13:1-14. doi: 10.1016/S0969-9961(03)00030-5

[257] Arnold JC, Salvatore MF. Exercise-mediated increase in nigral tyrosine hydroxylase is accompanied by increased nigral GFR-alpha1 and EAAC1 expression in aging rats. ACS Chem Neurosci. 2016;7:227-39. doi: 10.1021/acschemneuro.5b00282

[258] Baek DJ, Lee CB, Baek SS. Effect of treadmill exercise on social interaction and tyrosine hydroxylase expression in the attention-deficit/ hyperactivity disorder rats. J Exerc Rehabil. 2014;10:252-7. doi: 10.12965/jer.140162

[259] Tumer N, LaRochelle JS, Yurekli M. Exercise training reverses the age-related decline in tyrosine hydroxylase expression in rat hypothalamus. J Gerontol A Biol Sci Med Sci. 1997;52:B255-9. doi:

[260] Petzinger GM, Walsh JP, Akopian G, Hogg E, Abernathy A, Arevalo P, et al. Effects of treadmill exercise on dopaminergic transmission in the 1-methyl-4-phenyl1,2,3,6-tetrahydropyridine-lesioned mouse model of basal ganglia injury. J Neurosci. 2007;27:5291-300. doi: 10.1523/JNEUROSCI.1069-07.2007

[261] Groch S, Wilhelm I, Diekelmann S, Sayk F, Gais S, Born J. Contribution of norepinephrine to emotional memory consolidation during sleep. Psychoneuroendocrinology. 2011;36:1342-50. doi: 10.1016/j.psyneuen.2011.03.006

[262] Murchison CF, Zhang XY, Zhang WP, Ouyang M, Lee A, Thomas SA. A distinct role for norepinephrine in memory retrieval. Cell. 2004;117:131-43. doi: 10.1016/S00928674(04)00259-4

[263] O'Dell TJ, Connor SA, Guglietta R, Nguyen PV. betaAdrenergic receptor signaling and modulation of longterm potentiation in the mammalian hippocampus. Learn Mem. 2015;22:461-71. doi: 10.1101/lm.031088.113

[264] Brown BS, Payne T, Kim C, Moore G, Krebs P, Martin W. Chronic response of rat brain norepinephrine and serotonin levels to endurance training. J Appl Physiol Respir Environ Exerc Physiol. 1979;46:19-23. doi: 10.1152/jappl.1979.46.1.19

[265] Dunn AL, Reigle TG, Youngstedt SD, Armstrong RB, Dishman RK. Brain norepinephrine and metabolites after treadmill training and wheel running in rats. Med Sci Sports Exerc. 1996;28:204-9. doi: 10.1097/00005768199602000-00008

[266] Pagliari R, Peyrin L. Norepinephrine release in the rat frontal cortex under treadmill exercise: a study with microdialysis. J Appl Physiol (1985). 1995;78:2121-30. doi: 10.1152/jappl.1995.78.6.2121

[267] Sarbadhikari SN, Saha AK. Moderate exercise and chronic stress produce counteractive effects on different areas of the brain by acting through various neurotransmitter receptor subtypes: a hypothesis. Theor Biol Med Model. 2006;3:33. doi: 10.1186/1742-4682-3-33

[268] Semenova TP, Ivanov VA, Tret'yak TM. Brain levels of noradrenalin, dopamine, and serotonin in rats with different levels of motor activity. Neurosci Behav Physiol. 1981;11:153-5. doi: 10.1007/BF01182373

[269] Counts SE, Mufson EJ. Noradrenaline activation of neurotrophic pathways protects against neuronal amyloid toxicity. J Neurochem. 2010;113:649-60. doi: 10.1111/j.1471-4159.2010.06622.x

[270] Van Hoomissen JD, Holmes PV, Zellner AS, Poudevigne A, Dishman RK. Effects of $\beta$-Adrenoreceptor Blockade During Chronic Exercise on Contextual Fear Conditioning and mRNA for Galanin and Brain-Derived Neurotrophic Factor. Behav Neurosci. 2004;118:1378-90. doi: 10.1037/0735-7044.118.6.1378

[271] Ebrahimi S, Rashidy-Pour A, Vafaei AA, Akhavan MM. Central $\hat{\mathrm{I}}^{2}$-adrenergic receptors play an important role in the enhancing effect of voluntary exercise on learning and memory in rat. Behav Brain Res. 2010;208:189-93. doi: 10.1016/j.bbr.2009.11.032

[272] Chen MJ, Nguyen TV, Pike CJ, Russo-Neustadt AA. Norepinephrine induces BDNF and activates the PI-3K and MAPK cascades in embryonic hippocampal neurons. Cell Signal. 2007;19:114-28. doi: 10.1016/j.cellsig.2006.05.028

[273] Di Lieto A, Rantamaki T, Vesa L, Yanpallewar S, Antila $\mathrm{H}$, Lindholm $\mathrm{J}$, et al. The responsiveness of TrkB to 
BDNF and antidepressant drugs is differentially regulated during mouse development. PLoS One. 2012;7:e32869. doi: 10.1371/journal.pone.0032869

[274] Rantamaki T, Vesa L, Antila H, Di Lieto A, Tammela P, Schmitt A, et al. Antidepressant drugs transactivate TrkB neurotrophin receptors in the adult rodent brain independently of BDNF and monoamine transporter blockade. PLoS One. 2011;6:e20567. doi: 10.1371/journal.pone.0020567

[275] Liu X, Ye K, Weinshenker D. Norepinephrine Protects against Amyloid-beta Toxicity via TrkB. J Alzheimers Dis. 2015;44:251-60. doi: 10.3233/JAD-141062

[276] Heneka MT, Galea E, Gavriluyk V, Dumitrescu-Ozimek L, Daeschner J, O'Banion MK, et al. Noradrenergic depletion potentiates beta -amyloid-induced cortical inflammation: Implications for Alzheimer's disease. J Neurosci. 2002;22:2434-42. doi: 20026222

[277] Heneka MT, Nadrigny F, Regen T, Martinez-Hernandez A, Dumitrescu-Ozimek L, Terwel D, et al. Locus ceruleus controls Alzheimer's disease pathology by modulating microglial functions through norepinephrine. Proc Natl Acad Sci U S A. 2010;107:6058-63. doi: 10.1073/pnas.0909586107

[278] Lockrow J, Boger H, Gerhardt G, Aston-Jones G, Bachman D, Granholm AC. A noradrenergic lesion exacerbates neurodegeneration in a Down syndrome mouse model. J Alzheimers Dis. 2011;23:471-89. doi: 10.3233/JAD2010-101218

[279] Bondareff W, Mountjoy CQ, Roth M, Rossor MN, Iversen LL, Reynolds GP, et al. Neuronal degeneration in locus ceruleus and cortical correlates of Alzheimer disease. Alzheimer Dis Assoc Disord. 1987;1:256-62. doi: 10.1097/00002093-198701040-00005

[280] Matthews KL, Chen CP, Esiri MM, Keene J, Minger SL, Francis PT. Noradrenergic changes, aggressive behavior, and cognition in patients with dementia. Biol Psychiatry. 2002;51:407-16.

[281] Bharani KL, Derex R, Granholm AC, Ledreux A. A noradrenergic lesion aggravates the effects of systemic inflammation on the hippocampus of aged rats. PLoS One. 2017;12:e0189821. doi: 10.1371/journal.pone. 0189821

[282] Iyo M, Yamasaki T. The detection of age-related decrease of dopamine D1, D2 and serotonin 5-HT2 receptors in living human brain. Prog Neuropsychopharmacol Biol Psychiatry. 1993;17:415-21.

[283] Hasselbalch SG, Madsen K, Svarer C, Pinborg LH, Holm S, Paulson OB, et al. Reduced 5-HT2A receptor binding in patients with mild cognitive impairment. Neurobiol Aging. 2008;29:1830-8. doi: 10.1016/j.neurobiolaging.2007.04.011

[284] Lesch KP, Waider J. Serotonin in the modulation of neural plasticity and networks: implications for neurodevelopmental disorders. Neuron. 2012;76:175-91. doi: 10.1016/j.neuron.2012.09.013

[285] Yuen EY, Jiang Q, Chen P, Feng J, Yan Z. Activation of 5-HT2A/C receptors counteracts 5-HT1A regulation of n-methyl-D-aspartate receptor channels in pyramidal neurons of prefrontal cortex. J Biol Chem. 2008;283:17194-204. doi: 10.1074/jbc.M801713200

[286] Yuen EY, Jiang Q, Chen P, Gu Z, Feng J, Yan Z. Serotonin 5-HT1A receptors regulate NMDA receptor channels through a microtubule-dependent mechanism. J Neurosci. 2005;25:5488-501. doi: 10.1523/JNEUROS CI.1187-05.2005
[287] Chen MJ, Russo-Neustadt AA. Exercise activates the phosphatidylinositol 3-kinase pathway. Brain Res Mol Brain Res. 2005;135:181-93. doi: 10.1016/j.molbrainres.2004.12.001

[288] Chennaoui M, Grimaldi B, Fillion MP, Bonnin A, Drogou C, Fillion G, et al. Effects of physical training on functional activity of 5-HT $1 \mathrm{~B}$ receptors in rat central nervous system: role of 5-HT-moduline. Naunyn-Schmiedeberg's Archives of Pharmacology. 2000;361:600-4. doi: 10.1007/s002100000242

[289] Renoir T, Pang TYC, Zajac MS, Chan G, Du X, Leang $\mathrm{L}$, et al. Treatment of depressive-like behaviour in Huntington's disease mice by chronic sertraline and exercise. British Journal of Pharmacology. 2012;165:1375-89. doi: 10.1111/j.1476-5381.2011.01567.x

[290] Mattson MP, Maudsley S, Martin B. BDNF and 5-HT: a dynamic duo in age-related neuronal plasticity and neurodegenerative disorders. Trends Neurosci. 2004;27:589-94. doi: 10.1016/j.tins.2004.08.001

[291] Klempin F, Babu H, De Pietri Tonelli D, Alarcon E, Fabel K, Kempermann G. Oppositional effects of serotonin receptors 5-HT1a, 2, and 2c in the regulation of adult hippocampal neurogenesis. Front Mol Neurosci. 2010;3. doi: 10.3389/fnmol.2010.00014

[292] Klempin F, Beis D, Mosienko V, Kempermann G, Bader M, Alenina N. Serotonin is required for exercise-induced adult hippocampal neurogenesis. J Neurosci. 2013;33:8270-5. doi: 10.1523/JNEUROSCI.585512.2013

[293] Klempin F, Mosienko V, Matthes S, Villela DC, Todiras M, Penninger JM, et al. Depletion of angiotensin-converting enzyme 2 reduces brain serotonin and impairs the runninginduced neurogenic response. Cell Mol Life Sci. 2018. doi: 10.1007/s00018-018-2815-y

[294] Blandini F, Greenamyre JT, Fancellu R, Nappi G. Blockade of subthalamic glutamatergic activity corrects changes in neuronal metabolism and motor behavior in rats with nigrostriatal lesions. Neurol Sci. 2001;22:49-50. doi: $10.1007 / \mathrm{s} 100720170041$

[295] Bliss TV, Collingridge GL. A synaptic model of memory: long-term potentiation in the hippocampus. Nature. 1993;361:31-9. doi: 10.1038/361031a0

[296] Sah N, Peterson BD, Lubejko ST, Vivar C, van Praag H. Running reorganizes the circuitry of one-week-old adultborn hippocampal neurons. Sci Rep. 2017;7:10903. doi: 10.1038/s41598-017-11268-Z

[297] Vivar C, Peterson BD, van Praag H. Running rewires the neuronal network of adult-born dentate granule cells. Neuroimage. 2016;131:29-41. doi: 10.1016/j.neuroimage.2015.11.031

[298] Segovia G, Porras A, Del Arco A, Mora F. Glutamatergic neurotransmission in aging: a critical perspective. Mech Ageing Dev. 2001;122:1-29. doi: 10.1016/S00476374(00)00225-6

[299] Blandini F, Greenamyre JT, Nappi G. The role of glutamate in the pathophysiology of Parkinson's disease. Funct Neurol. 1996;11:3-15.

[300] Francis PT. Glutamatergic systems in Alzheimer's disease. Int J Geriatr Psychiatry. 2003;18:S15-21. doi: $10.1002 /$ gps.934

[301] Mora F, Segovia G, del Arco A. Aging, plasticity and environmental enrichment: Structural changes and neurotransmitter dynamics in several areas of the brain. Brain Research Reviews. 2007;55:78-88. doi: 10.1016/j.brainresrev.2007.03.011 
[302] Michaelis EK. Molecular biology of glutamate receptors in the central nervous system and their role in excitotoxicity, oxidative stress and aging. Prog Neurobiol. 1998;54:369-415. doi: 10.1016/S0301-0082(97) 00055-5

[303] Suen PC, Wu K, Levine ES, Mount HT, Xu JL, Lin SY, et al. Brain-derived neurotrophic factor rapidly enhances phosphorylation of the postsynaptic N-methylD-aspartate receptor subunit 1. Proc Natl Acad Sci U S A. 1997;94:8191-5. doi: 10.1073/pnas.94.15.8191

[304] Fox CJ, Russell KI, Wang YT, Christie BR. Contribution of NR2A and NR2B NMDA subunits to bidirectional synaptic plasticity in the hippocampus in vivo. Hippocampus. 2006;16:907-15. doi: 10.1002/hipo.20230

[305] Luscher C, Malenka RC. NMDA receptor-dependent long-term potentiation and long-term depression (LTP/LTD). Cold Spring Harb Perspect Biol. 2012;4:a005710-a. doi: 10.1101/cshperspect.a005710

[306] Sun XY, Tuo QZ, Liuyang ZY, Xie AJ, Feng XL, Yan $X$, et al. Extrasynaptic NMDA receptor-induced tau overexpression mediates neuronal death through suppressing survival signaling ERK phosphorylation. Cell Death Dis. 2016;7:e2449. doi: 10.1038/cddis.2016.329

[307] Biedermann S, Fuss J, Zheng L, Sartorius A, FalfanMelgoza C, Demirakca T, et al. In vivo voxel based morphometry: detection of increased hippocampal volume and decreased glutamate levels in exercising mice. Neuroimage. 2012;61:1206-12. doi: 10.1016/j.neuroimage.2012.04.010

[308] Herbst EA, Holloway GP. Exercise increases mitochondrial glutamate oxidation in the mouse cerebral cortex. Appl Physiol Nutr Metab. 2016;41:799-801. doi: 10.1139/apnm-2016-0033

[309] Mourao FA, Leite HR, de Carvalho LE, Ferreira EVTH, Pinto MC, de Castro Medeiros D, et al. Neuroprotective effect of exercise in rat hippocampal slices submitted to in vitro ischemia is promoted by decrease of glutamate release and pro-apoptotic markers. J Neurochem. 2014;131:65-73. doi: 10.1111/jnc.12786

[310] Finkbeiner S, Tavazoie SF, Maloratsky A, Jacobs KM, Harris KM, Greenberg ME. CREB: a major mediator of neuronal neurotrophin responses. Neuron. 1997;19:103147. doi: 10.1016/S0896-6273(00)80395-5

[311] Hetman M, Kanning K, Cavanaugh JE, Xia Z. Neuroprotection by brain-derived neurotrophic factor is mediated by extracellular signal-regulated kinase and phosphatidylinositol 3-kinase. J Biol Chem. 1999;274:22569-80. doi: 10.1074/jbc.274.32.22569

[312] Behrens MM, Strasser U, Koh JY, Gwag BJ, Choi DW. Prevention of neuronal apoptosis by phorbol ester-induced activation of protein kinase C: blockade of p38 mitogenactivated protein kinase. Neuroscience. 1999;94:917-27. doi: 10.1016/S0306-4522(99)00212-2

[313] Pizzorusso T, Ratto GM, Putignano E, Maffei L. Brain-derived neurotrophic factor causes cAMP response element-binding protein phosphorylation in absence of calcium increases in slices and cultured neurons from rat visual cortex. J Neurosci. 2000;20:2809-16. doi: 10.1523/JNEUROSCI.20-08-02809.2000

[314] Yoshii A, Constantine-Paton M. Postsynaptic BDNFTrkB signaling in synapse maturation, plasticity, and disease. Dev Neurobiol. 2010;70:304-22. doi: 10.1002/dneu.20765

[315] Rendeiro C, Rhodes JS. A new perspective of the hippocampus in the origin of exercise-brain inter- actions. Brain Struct Funct. 2018;223:2527-45. doi: 10.1007/s00429-018-1665-6

[316] Almeida RD, Manadas BJ, Melo CV, Gomes JR, Mendes CS, Graos MM, et al. Neuroprotection by BDNF against glutamate-induced apoptotic cell death is mediated by ERK and PI3-kinase pathways. Cell Death Differ. 2005;12:1329-43. doi: 10.1038/sj.cdd.4401662

[317] Franke TF, Kaplan DR, Cantley LC. PI3K: downstream AKTion blocks apoptosis. Cell. 1997;88:435-7. doi: 10.1016/S0092-8674(00)81883-8

[318] Caldeira MV, Melo CV, Pereira DB, Carvalho RF, Carvalho $\mathrm{AL}$, Duarte $\mathrm{CB}$. BDNF regulates the expression and traffic of NMDA receptors in cultured hippocampal neurons. Mol Cell Neurosci. 2007;35:208-19. doi: 10.1016/j.mcn.2007.02.019

[319] Zakharenko SS, Patterson SL, Dragatsis I, Zeitlin SO, Siegelbaum SA, Kandel ER, et al. Presynaptic BDNF required for a presynaptic but not postsynaptic component of LTP at hippocampal CA1-CA3 synapses. Neuron. 2003;39:975-90. doi: 10.1016/S0896-6273(03)00543-9

[320] Rosahl TW, Geppert M, Spillane D, Herz J, Hammer RE, Malenka RC, et al. Short-term synaptic plasticity is altered in mice lacking synapsin I. Cell. 1993;75:661-70. doi: 10.1016/0092-8674(93)90487-B

[321] Cesca F, Baldelli P, Valtorta F, Benfenati F. The synapsins: key actors of synapse function and plasticity. Prog Neurobiol. 2010;91:313-48. doi: 10.1016/j.pneurobio.2010.04.006

[322] Chin LS, Li L, Ferreira A, Kosik KS, Greengard P. Impairment of axonal development and of synaptogenesis in hippocampal neurons of synapsin I-deficient mice. Proc Natl Acad Sci U S A. 1995;92:9230-4. doi: 10.1073/pnas.92.20.9230

[323] Kang H, Schuman EM. A requirement for local protein synthesis in neurotrophin-induced hippocampal synaptic plasticity. Science. 1996;273:1402-6. doi: 10.1126/science.273.5280.1402

[324] Lawson VH, Bland BH. The role of the septohippocampal pathway in the regulation of hippocampal field activity and behavior: analysis by the intraseptal microinfusion of carbachol, atropine, and procaine. Exp Neurol. 1993;120:132-44. doi: 10.1006/exnr.1993.1047

[325] Lee MG, Chrobak JJ, Sik A, Wiley RG, Buzsaki G. Hippocampal theta activity following selective lesion of the septal cholinergic system. Neuroscience. 1994;62:103347. doi: 10.1016/0306-4522(94)90341-7

[326] Rossi C, Angelucci A, Costantin L, Braschi C, Mazzantini M, Babbini F, et al. Brain-derived neurotrophic factor (BDNF) is required for the enhancement of hippocampal neurogenesis following environmental enrichment. Eur J Neurosci. 2006;24:1850-6. doi: 10.1111/j.14609568.2006.05059.x

[327] Zhang L, Fang Y, Lian Y, Chen Y, Wu T, Zheng $\mathrm{Y}$, et al. Brain-derived neurotrophic factor ameliorates learning deficits in a rat model of Alzheimer's disease induced by abeta 1-42. PLoS One. 2015;10:e0122415. doi: 10.1371/journal.pone.0122415

[328] Mustroph ML, Chen S, Desai SC, Cay EB, DeYoung EK, Rhodes JS. Aerobic exercise is the critical variable in an enriched environment that increases hippocampal neurogenesis and water maze learning in male C57BL/6J mice. Neuroscience. 2012;219:62-71. doi: 10.1016/j.neuroscience.2012.06.007

[329] Fahey B, Barlow S, Day JS, O'Mara SM. Interferon-alphainduced deficits in novel object recognition are rescued 
by chronic exercise. Physiol Behav. 2008;95:125-9. doi: 10.1016/j.physbeh.2008.05.008

[330] Jackson PA, Pialoux V, Corbett D, Drogos L, Erickson KI, Eskes GA, et al. Promoting brain health through exercise and diet in older adults: a physiological perspective. J Physiol. 2016;594:4485-98. doi: 10.1113/JP271270

[331] Frank MG, Barrientos RM, Biedenkapp JC, Rudy JW, Watkins LR, Maier SF. mRNA up-regulation of MHC II and pivotal pro-inflammatory genes in normal brain aging. Neurobiol Aging. 2006;27:717-22. doi: 10.1016/j.neurobiolaging.2005.03.013

[332] Griffin R, Nally R, Nolan Y, McCartney Y, Linden $\mathrm{J}$, Lynch MA. The age-related attenuation in longterm potentiation is associated with microglial activation. J Neurochem. 2006;99:1263-72. doi: 10.1111/j.14714159.2006.04165.x

[333] Perry VH, Matyszak MK, Fearn S. Altered antigen expression of microglia in the aged rodent CNS. Glia. 1993;7:60-7. doi: 10.1002/glia.440070111

[334] Whiteman AS, Young DE, Budson AE, Stern CE, Schon K. Entorhinal volume, aerobic fitness, and recognition memory in healthy young adults: A voxel-based morphometry study. Neuroimage. 2016;126:229-38. doi: 10.1016/j.neuroimage.2015.11.049

[335] Whiteman AS, Young DE, He X, Chen TC, Wagenaar $\mathrm{RC}$, Stern $\mathrm{CE}$, et al. Interaction between serum BDNF and aerobic fitness predicts recognition memory in healthy young adults. Behav Brain Res. 2014;259:302-12. doi: 10.1016/j.bbr.2013.11.023

[336] Chang YK, Labban JD, Gapin JI, Etnier JL. The effects of acute exercise on cognitive performance: a meta-analysis. Brain Res. 2012;1453:87-101. doi: 10.1016/j.brainres.2012.02.068

[337] Cox EP, O’Dwyer N, Cook R, Vetter M, Cheng HL, Rooney K, et al. Relationship between physical activity and cognitive function in apparently healthy young to middle-aged adults: A systematic review. J Sci Med Sport. 2016;19:616-28. doi: 10.1016/j.jsams.2015.09.003

[338] Tsai CL, Pan CY, Chen FC, Wang CH, Chou FY. Effects of acute aerobic exercise on a task-switching protocol and brain-derived neurotrophic factor concentrations in young adults with different levels of cardiorespiratory fitness. Exp Physiol. 2016;101:836-50. doi: 10.1113/EP085682

[339] Wrann CD. FNDC5/irisin - their role in the nervous system and as a mediator for beneficial effects of exercise on the brain. Brain Plast. 2015;1:55-61. doi: 10.3233/BPL150019

[340] Wrann CD, White JP, Salogiannnis J, Laznik-Bogoslavski $\mathrm{D}, \mathrm{Wu} \mathrm{J}, \mathrm{Ma} \mathrm{D}$, et al. Exercise induces hippocampal BDNF through a PGC-1alpha/FNDC5 pathway. Cell Metab. 2013;18:649-59. doi: 10.1016/j.cmet.2013.09.008

[341] Bostrom P, Wu J, Jedrychowski MP, Korde A, Ye L, Lo $\mathrm{JC}$, et al. A PGC1-alpha-dependent myokine that drives brown-fat-like development of white fat and thermogenesis. Nature. 2012;481:463-8. doi: 10.1038/nature10777

[342] Briken S, Rosenkranz SC, Keminer O, Patra S, Ketels $\mathrm{G}$, Heesen C, et al. Effects of exercise on Irisin, BDNF and IL-6 serum levels in patients with progressive multiple sclerosis. J Neuroimmunol. 2016;299:53-8. doi: 10.1016/j.jneuroim.2016.08.007

[343] Finck BN, Kelly DP. PGC-1 coactivators: inducible regulators of energy metabolism in health and disease. J Clin Invest. 2006;116:615-22. doi: 10.1172/JCI27794

[344] Papp C, Pak K, Erdei T, Juhasz B, Seres I, Szentpeteri A, et al. Alteration of the irisin-brain-derived neurotrophic factor axis contributes to disturbance of mood in COPD patients. Int J Chron Obstruct Pulmon Dis. 2017;12:202333. doi: 10.2147/COPD.S135701

[345] Chen M, Do H. Wnt Signaling in Neurogenesis during Aging and Physical Activity. Brain Sci. 2012;2:745-68. doi: 10.3390/brainsci2040745

[346] Duman RS, Voleti B. Signaling pathways underlying the pathophysiology and treatment of depression: novel mechanisms for rapid-acting agents. Trends Neurosci. 2012;35:47-56. doi: 10.1016/j.tins.2011.11.004

[347] Baranowski BJ, MacPherson REK. Acute exercise induced BDNF-TrkB signaling is intact in the prefrontal cortex of obese glucose intolerant male mice. Appl Physiol Nutr Metab. 2018. doi: 10.1139/apnm-2018-0108

[348] Russo-Neustadt A, Ha T, Ramirez R, Kesslak JP. Physical activity-antidepressant treatment combination: impact on brain-derived neurotrophic factor and behavior in an animal model. Behav Brain Res. 2001;120:87-95. doi: 10.1016/S0166-4328(00)00364-8

[349] Russo-Neustadt AA, Beard RC, Huang YM, Cotman CW. Physical activity and antidepressant treatment potentiate the expression of specific brain-derived neurotrophic factor transcripts in the rat hippocampus. Neuroscience. 2000;101:305-12. doi: 10.1016/S0306-4522(00)00349-3

[350] Wu CW, Chang YT, Yu L, Chen HI, Jen CJ, Wu $\mathrm{SY}$, et al. Exercise enhances the proliferation of neural stem cells and neurite growth and survival of neuronal progenitor cells in dentate gyrus of middle-aged mice. J Appl Physiol (1985). 2008;105:1585-94. doi: 10.1152/japplphysiol.90775.2008

[351] MacRae PG, Spirduso WW, Walters TJ, Farrar RP, Wilcox RE. Endurance training effects on striatal D2 dopamine receptor binding and striatal dopamine metabolites in presenescent older rats. Psychopharmacology (Berl). 1987;92:236-40. doi: 10.1007/ BF00177922

[352] Gomez-Merino D, Bequet F, Berthelot M, Chennaoui M, Guezennec CY. Site-dependent effects of an acute intensive exercise on extracellular 5-HT and 5-HIAA levels in rat brain. Neurosci Lett. 2001;301:143-6. doi: 10.1016/S0304-3940(01)01626-3

[353] Real CC, Ferreira AFB, Hernandes MS, Britto LRG, Pires RS. Exercise-induced plasticity of AMPA-type glutamate receptor subunits in the rat brain. Brain Research. 2010;1363:63-71. doi: 10.1016/j.brainres.2010.09.060

[354] Tozuka Y, Fukuda S, Namba T, Seki T, Hisatsune T. GABAergic excitation promotes neuronal differentiation in adult hippocampal progenitor cells. Neuron. 2005;47:803-15. doi: 10.1016/j.neuron.2005.08.023

[355] Schoenfeld TJ, Rada P, Pieruzzini PR, Hsueh B, Gould E. Physical exercise prevents stress-induced activation of granule neurons and enhances local inhibitory mechanisms in the dentate gyrus. J Neurosci. 2013;33:7770-7. doi: 10.1523/JNEUROSCI.5352-12.2013

[356] Kurosawa M, Okada K, Sato A, Uchida S. Extracellular release of acetylcholine, noradrenaline and serotonin increases in the cerebral cortex during walking in conscious rats. Neurosci Lett. 1993;161:73-6. doi: 10.1016/0304-3940(93)90143-9

[357] Nakajima K, Uchida S, Suzuki A, Hotta H, Aikawa Y. The effect of walking on regional blood flow and acetylcholine in the hippocampus in conscious rats. Auton Neurosci. 2003;103:83-92. doi: 10.1016/S1566-0702(02)00263-1 